\title{
An Engineering Perspective of External Cardiac Loop Recorder: A Systematic Review
}

\author{
Avvaru Srinivasulu ${ }^{1}$ and N. Sriraam ${ }^{2}$ \\ ${ }^{1}$ Department of Electronics and Instrumentation Engineering, GITAM University, Bangalore Campus, Bangalore, India \\ ${ }^{2}$ Center for Medical Electronics and Computing, M.S. Ramaiah Institute of Technology, Bangalore, India \\ Correspondence should be addressed to N. Sriraam; sriraam@msrit.edu
}

Received 29 June 2016; Accepted 28 September 2016

Academic Editor: Sotirios Korossis

Copyright $\odot 2016$ A. Srinivasulu and N. Sriraam. This is an open access article distributed under the Creative Commons Attribution License, which permits unrestricted use, distribution, and reproduction in any medium, provided the original work is properly cited.

External cardiac loop recorder (ELR) is a kind of ECG monitoring system that records cardiac activities of a subject continuously for a long time. When the heart palpitations are not the frequent and nonspecific character, it is difficult to diagnose the disease. In such a case, ELR is used for long-term monitoring of heart signal of the patient. But the cost of ELR is very high. Therefore, it is not prominently available in developing countries like India. Since the design of ELR includes the ECG electrodes, instrumentation amplifier, analog to digital converter, and signal processing unit, a comparative review of each part of the ELR is presented in this paper in order to design a cost effective, low power, and compact kind of ELR. This review will also give different choices available for selecting and designing each part of the ELR system. Finally, the review will suggest the better choice for designing a cost effective external cardiac loop recorder that helps to make it available even for rural people in India.

\section{Introduction}

Norman J. Holter (1914-1983), the famous American biophysicist, introduced a remote cardiac telemetry first time in the 1940s [1]. The Holter system was developed for home ECG monitoring of patients with suspected cardiac arrhythmias. The original Holter monitor had analog patient interface electronics, a $75 \mathrm{lb}$ backpack with a reel-to-reel FM tape recorder, and large batteries. It was the first monitoring system that could record single ECG lead 24-48 hours [2] and analyse ambulatory ECG data outside a standard hospital or outpatient care setting. At present, the Holter monitors are available in the market with the cost of about \$369-\$2490 [3] depending on their features and the cost of Holter test is around \$175-\$250 [4] if it is interpreted by a cardiologist. The clinical need to monitor ambulatory ECG has resulted in advances in technology that now allow us to monitor heart rhythms remotely through a wide variety of devices, including ambulatory external monitors and implantable event recorders.

Implantable/insertable loop recorder (ILR) was developed first time by Medtronic's Reveal [5] (the world's first implantable diagnostic device). The Reveal ILR detects ECGs during the actual episode, which may allow physicians to take decisions or confirm an abnormal heart rhythm more definitively. Because it could be worn continuously for 14 months, the likelihood of capturing heart rhythm during an infrequent episode was probable. The cost per diagnosis using ILR is around $\$ 6,158$ [6]. The cause of seizure-like symptoms or related symptoms was diagnosed with the Reveal ILR that may also result in fewer physician and emergency room visits and reduce the number of tests involved when trying to diagnose their cause. Most importantly, diagnosing the cause helps in early treatment effectively. Even though ILR was useful in monitoring of ECG for the detection of abnormal episodes, it had some disadvantages that include the following: (1) a minor surgical procedure is needed, (2) there is always difficulty in differentiating supraventricular from ventricular arrhythmias, (3) under- or oversensing may exhaust the memory of the ILR, and (4) cost of the device is more.

To overcome the limitations of both the Holter and ILR, an intermittent patient- or event-activated recorder was 
TABLE 1: Comparison among Holter monitor, ELR, and ILR.

\begin{tabular}{|c|c|c|c|c|}
\hline & Advantages & Limitations & Indications & Diagnostic yield \\
\hline Holter monitor & $\begin{array}{l}\text { Low cost, continuous } \\
\text { monitoring }\end{array}$ & $\begin{array}{l}\text { Short duration of } \\
\text { monitoring with low } \\
\text { diagnostic yield }\end{array}$ & $\begin{array}{l}\text { Patients with very frequent } \\
\text { symptoms ( } \geq 1 \text { week) }\end{array}$ & $6-22 \%$ \\
\hline $\begin{array}{l}\text { External loop } \\
\text { recorder }\end{array}$ & $\begin{array}{l}\text { Retrospective and } \\
\text { prospective ECG records, } \\
\text { possibility to record } \\
\text { asymptomatic arrhythmias } \\
\text { automatically }\end{array}$ & $\begin{array}{l}\text { Poor recordings, poor } \\
\text { patient compliance to } \\
\text { wearing device, continuous } \\
\text { device maintenance } \\
\text { required }\end{array}$ & $\begin{array}{l}\text { Compliant patients with } \\
\text { intersymptom interval } \leq 4 \\
\text { weeks }\end{array}$ & $24-47 \%$ \\
\hline $\begin{array}{l}\text { Implantable } \\
\text { loop recorder }\end{array}$ & $\begin{array}{l}\text { Prolonged monitoring } \\
\text { without external electrodes, } \\
\text { highest diagnostic yield }\end{array}$ & $\begin{array}{l}\text { Invasive implantation with } \\
\text { risk of local complications, } \\
\text { high cost }\end{array}$ & $\begin{array}{l}\text { Early phase of evaluation of } \\
\text { patients with recurrent } \\
\text { syncope of uncertain origin } \\
\text { that have absence of high } \\
\text { risk criteria that require } \\
\text { immediate hospitalization } \\
\text { or intensive evaluation and } \\
\text { a likely recurrence within } \\
\text { device battery longevity }\end{array}$ & $43-78 \%$ \\
\hline
\end{tabular}

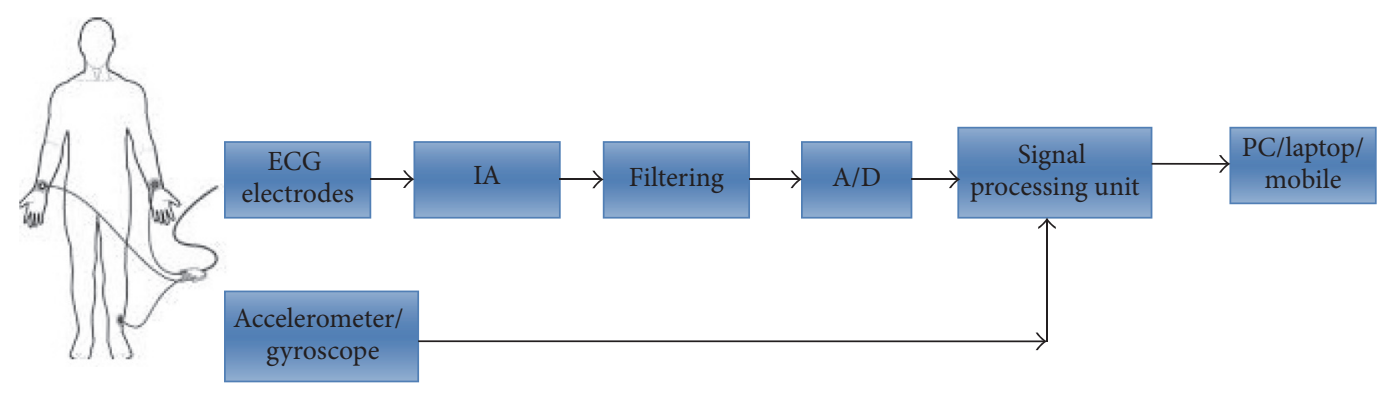

FIGURE 1: Block diagram of external cardiac loop recorder.

developed. This is also referred to as event monitor or external loop recorder (ELR). The ELR is smaller than Holter in size and is attached to the patient through chest electrodes and records the data when it is activated by the patient or by an automatic trigger that detects irregular heart rates. It is used for monitoring up to 14-30 days. The cost of ELR is \$627 and cost per diagnosis using ELR is around \$265,9 [7]. The use of ELR avoids the surgical implantation of electrodes. But the activation of the device every time by the patient is difficult unless the autotrigger is used. The autotrigger activates the device as it is programmed which is built into the monitor. Therefore during infrequent symptoms, there is a more chance of missing the activation of the device. This may not give enough information for effective diagnosis. After recording using any of the above-mentioned systems, the data is sent to the central monitoring station where the data is loaded in the computer and analysed. Finally, the reports are sent to the doctor for a final decision or for further tests to detect and confirm the disease. As mentioned above, ELR is providing the noninvasive diagnosis by long-term monitoring. Even the cost of design is less, the ELR test cost is high. Further, the recorded data has to be sent to the specialist to analyse the data which increase the cost further. And there is no option for autosending the recorded data or analysed data to the doctor. The comparison among Holter, ILR, and ELR is given [8] in Table 1.

In Table 2 some of the available ILR and ELR products are given $[5,9-16]$.

The mentioned products in Table 2 are very expensive and most of them are not significantly available in India. Distributors are there all over India, but they are providing only a few products like Medtronic SpiderView, SEEQ MCT, Piix NUVANT MCT, GE Healthcare MARS, SEER 1000, SEER Light, Omron HCG801, and BPL cardiac loop recorder monitor. Therefore, a systematic review on internal parts of ECG monitoring system is required to design a cost effective ambulatory ECG monitoring system with an accurate measurement, portable and wearable one as explained in the following sections.

\section{Designing of External Cardiac Loop Recorder}

The design of external cardiac loop recorder consists of ECG electrodes, instrumentation amplifier, filtering, analog to digital converter, and signal processing unit. PC/laptop/mobile is also used to analyse the data. The major blocks and connection of them are shown in Figure 1. 
TABLE 2: ILR \& ELR products available.

\begin{tabular}{|c|c|c|c|}
\hline Device/company & Mode & Expected monitoring duration & $\begin{array}{l}\text { Max continuous recording } \\
\text { period }\end{array}$ \\
\hline Reveal Plus 9526/Medtronic & Implantable & 14 months & - \\
\hline Reveal DX/Medtronic & Implantable & 3 years & $42 \mathrm{~min}$ \\
\hline Reveal XT/Medtronic & Implantable & 3 years & $42 \mathrm{~min}$ \\
\hline Reveal LINQ/Medtronic & Implantable & 3 years & - \\
\hline Sleuth/Transoma & Implantable & 28 months & $630 \mathrm{~min}$ \\
\hline Confirm DM2100/St. Jude & Implantable & 3 years & $48 \min$ (147 episodes) \\
\hline Confirm DM 2102/St. Jude & Implantable & 3 years & $48 \min$ (147 episodes) \\
\hline MCOT/CardioNet & External & Few weeks & 21-day continuous monitoring \\
\hline LifeStar ACT/LifeWatch & External & Few weeks & 21-day retrievable monitoring \\
\hline LifeStar/LifeWatch & External & Few weeks & $10 \mathrm{~min}$ \\
\hline eVolution/eCardio & External & Few weeks & $30 \mathrm{~min}$ \\
\hline 3300 BT/Vitaphone & External & Few weeks & $20 \mathrm{~min}$ \\
\hline V-PATCH/Medical System & External & Few weeks & $30 \mathrm{~h}$ \\
\hline King of the Heart/Instrumedics & External & Few weeks & $6 \mathrm{~min}$ \\
\hline SpiderFlash/Sorin & External & Few weeks & Several hours \\
\hline Cardiocall/Reynolds Esaote & External & Few weeks & $18 \mathrm{~min}$ \\
\hline Super/I-Cardia & External & Depends on patient compliance & 2 recordings \\
\hline Cardio PAL/Medicomp & External & Depends on patient compliance & - \\
\hline SEEQ MCT/Medtronics & External & 30 days & - \\
\hline Piix NUVANT MCT/Corventis & External & 7 days & - \\
\hline HCG801/Omron & External & $\begin{array}{l}30 \text { seconds can be made when } \\
\text { symptoms occur }\end{array}$ & $\begin{array}{l}30 \mathrm{sec} \text { window indication, } \\
125 \mathrm{MB} \text { memory required }\end{array}$ \\
\hline SEER 1000/GE Healthcare & External & $\begin{array}{l}24 \mathrm{~h} \text { or } 48 \mathrm{~h} \text { or } 3 \text { days (three } \\
\text { modes are available) }\end{array}$ & Nonremovable digital memory \\
\hline SEER Light/GE Healthcare & External & $24 \mathrm{~h}$ ( $48 \mathrm{~h}$ for SEER Light extent) & $32 \mathrm{MB}$ memory required \\
\hline
\end{tabular}

The ECG signal is acquired from the chest electrodes and is amplified by the instrumentation amplifier. The amplified signal is filtered by the suitable filter to remove the noise. Mostly band pass filter is used for noise removal. Later, an analog to digital converter converts the filtered signal into a digital form which is suitable to process signal by the processor. A signal processing unit is used for processing and feature extraction of the signal to find the normal and abnormal conditions of the patient. For the effective detection of the abnormal conditions during daily activities accelerometer and/or gyroscope is also used along with the chest electrodes. By correlating the signals from chest electrodes and accelerometer/gyroscope, the abnormality of the patient can be defined. The signal processing unit is connected to the PC/laptop/mobile or system on chip (SoC) where the open source software is installed and used for displaying, processing, and saving the data. Further, communication with the doctor can be provided using wireless technology which helps to develop the smart city. The comparative study of each block is explained in following sections.

2.1. ECG Electrodes. Basically, disposal electrodes that may be $\mathrm{Ag} / \mathrm{AgCl}$ gel type wet sensors or dry sensors are used for acquiring biopotentials from heart. The gel type disposable

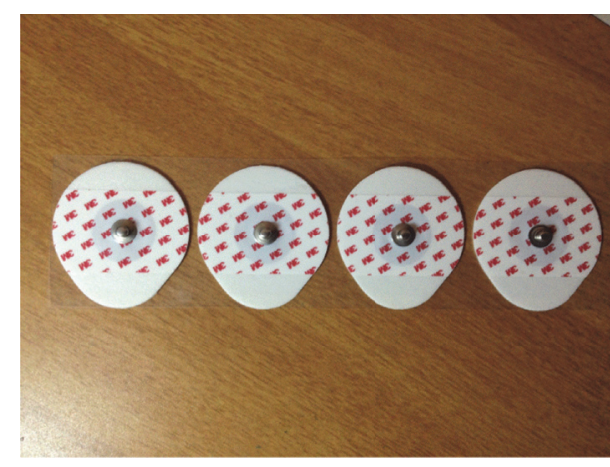

FIgure 2: Disposal Ag/AgCl electrodes.

electrodes have a circular contact. The close electrode placement is allowed by small vinyl backing where necessary and a slightly less firm adhesive allows ouchless removal. The electrodes incorporate liquid electrolyte gel and moderately high chloride salt concentration for quick and accurate readings. These disposable electrodes shown in Figure 2 provide the same signal transmission as reusable electrodes, with added convenience. Each peel and stick electrode is 


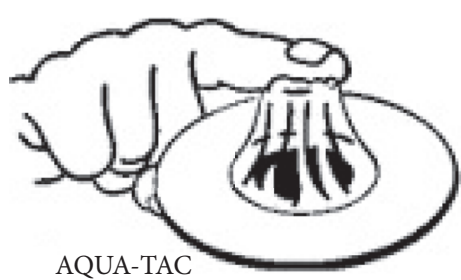

36 months

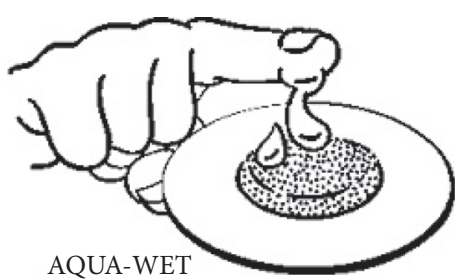

24 months

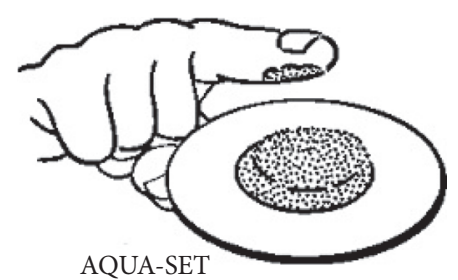

24 months

FIGURE 3: SKINTACT electrodes.

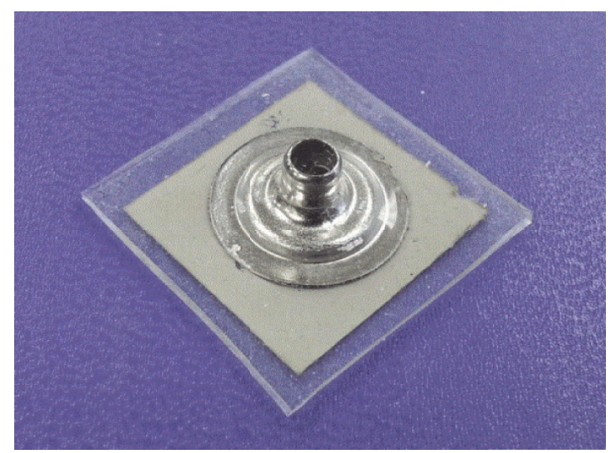

FIGURE 4: Dry electrode.

pregelled and designed for one use only. It is very cost effective compared to other electrodes. It is easily attachable to the subject himself/herself and there will not be any assistance needed. The placement of electrodes is also simple and only three electrodes at a time are required for two lead ECG acquisition systems as one electrode is the reference. These electrodes can be used for longer periods depending on the comfort level of the subject.

SKINTACT electrodes [73] shown in Figure 3 are available in the market with three different gels: AQUA-TAC electrode with solid adhesive gel provides $100 \%$ contact with skin surface, AQUA-WET electrode with liquid gel provides fast pickup of ECG signal which is preferred for short term monitoring, and AQUA-SET electrode with solid wet gel is used for long-term monitoring.

North Carolina State University researchers [74] had developed a new dry sensor shown in Figure 4 for longterm ECG and EMG monitoring. This device has relied on elastic conductors made from silver nanowires embedded in a pliable polymer.

Imec and Holst Centre introduced the polymer dry electrodes [75] shown in Figure 5 fabricated from ethylene propylene diene monomer (EPDM) rubber which offers a high user comfort and high conductivity.

PDMS (polydimethylsiloxane) based surface electrode shown in Figure 6 was designed [76] for the long-term and unsupervised monitoring. This electrode did not show negative influence on skin even it was worn for one week.

Apart from wet and dry electrodes, there are noncontact electrodes called capacitive electrodes. These were fabricated

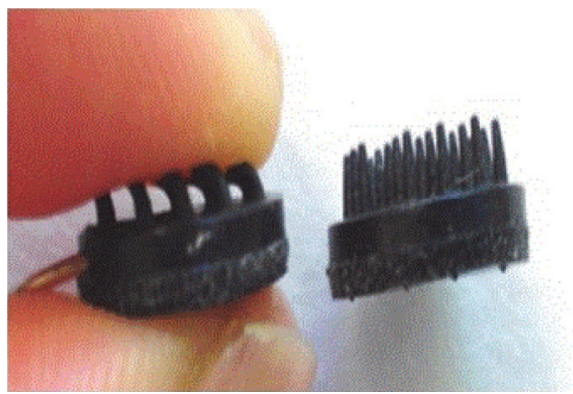

Figure 5: Polymer dry electrodes.

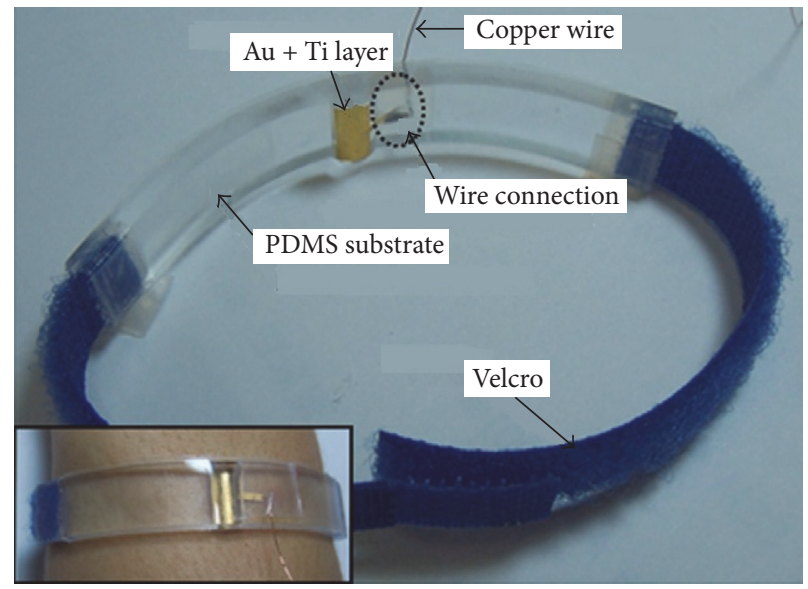

FIgURE 6: PDMS surface electrode.

on silicon with a thermally grown silicon dioxide as the dielectric layer. Dry capacitive electrodes were used for short-term ECG monitoring [77]. A new class of bioelectric sensors was developed by quantum applied science and research (QUASAR) in 2002. These electrodes were capacitively coupled with the body by incorporating the sensors into shirts, elastic belts, and glasses. The QUASAR twogeneration electrodes are shown in Figure 7(a). The firstgeneration electrode IBEvl is a larger, square sensor $\left(1^{\prime \prime} \times 1^{\prime \prime}\right)$ used to measure bioelectric potentials through T-shirt [78]. The second-generation electrode IBEv2 was developed as a small circular shape sensor shown in Figure 7(b). 


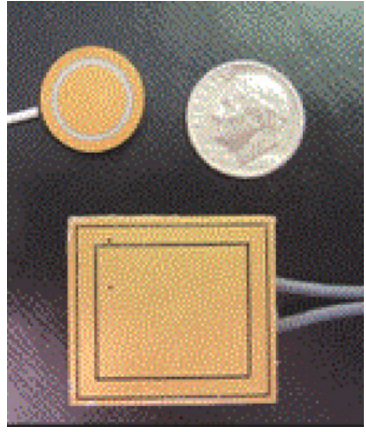

(a)

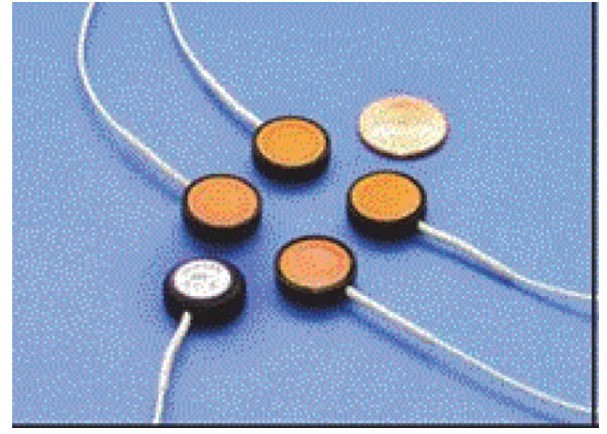

(b)

FIgURE 7: (a) QUASAR IBEv1 electrodes; (b) QUASAR IBEv2 electrodes.

2.2. Accelerometers and Gyroscopes. Accelerometers and gyroscopes are also used along with dry or wet sensors for cancelling muscle contraction interferences, to measure heart rate under different activities like stress, movements, and so forth. The accelerometer is a 3 -axis one. It is used in tilt-sensing applications, as well as dynamic acceleration resulting from motion or shock to measure the static acceleration of gravity. In previous work done the people used the accelerometer for different purposes. In previous work done, the people used the accelerometer for different purposes. ADXL335 triaxial accelerometer $[9,79]$ and triaxial accelerometer MotionPodTM by MOVEA were used for removal of motion artefacts. SDI1221, a low cost, integrated 1 -axis accelerometer, was used in zero to medium frequency instrumentation applications to provide extremely low noise $(5 \mu \mathrm{g} / \sqrt{ } \mathrm{Hz})$ [80]. A triple axis accelerometer [81-83] and MMA7260QT [84] were used in telehealth monitoring. ADXL330 was used in deciding of the cardiac disease $[85,86]$. Bosch BMA180 accelerometer was used in human behaviour tracing [87]. A triple axis accelerometer [81, 83, 88-90], ADXL345 [91], and ADXL330 [92] were used in activity recognition. MC301 made by Wacoh was used in ambulatory monitoring to find human posture and walking velocity [93]. MMA8451Q (Austin, TX, USA), a triple axis, low power, capacitive digital accelerometer (freescale semiconductor) [94], a triaxial accelerometer (patch sensor device designed by Vital Connect, Inc. (Campbell, CA)) [95], and inbuilt on-board 3-axis accelerometer SCA3000 [96] were used in extraction of respiratory rate. And also a triaxial accelerometer was used to measure the body movements [90] or daily stress [97] and for left ventricular functions monitoring [98]. A triaxial gait accelerometer MMA7260Q (freescale semiconductor, Austin, TX, USA) [99], piezoelectric foils [100], and Pegasus activity monitors developed by ETB, UK, were used for time-frequency analysis of heart rate. Triaxial accelerometer ADXL335 $[9,79]$ and MotionPodTM by MOVEA [98] were used as the reference for removing motion artefact by adaptive filtering algorithm (LMS or ANC) in acquiring of ECG during treadmill exercise. Apart from these, a triaxial accelerometer (LIS344ALH, ST Microelectronics) was used for seismocardiography.

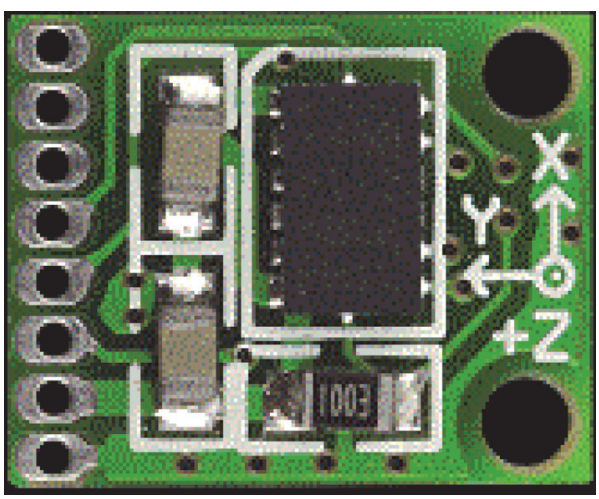

FIgURE 8: 3-axis accelerometer ADXL345.

Among all the accelerometers mentioned in Table 3, the model ADXL345 shown in Figure 8 can be selected because of less power consumption and better full scale range with 2-3.6 V supply voltage. In ECG monitoring, the accelerometer is used to get the change in acceleration due to body movements during daily activities. This is helpful in detecting the arrhythmias. Finally, the heart rate measured by disposal electrodes and the accelerometer readings will be correlated. Using this information alerts or notifications are sent.

The gyroscope is used to find the tilt in position when there is motion in the body. This is required for monitoring of ECG during daily activities. In previous work, gyroscopes were used in different applications like L3G4200D gyroscope used for head movement tracking along with accelerometer and magnetometer [17]. Gyroscope and accelerometer inbuilt MEMS chip [101] were used in robotic arm control by detecting the motion of arm [102] and vehicle speed control [103]. Ring laser gyroscope [104] and microgyroscope [105] are advanced gyros used for various applications. In cardiac applications, gyroscope was used for monitoring electric and mechanical functioning of heart [106] (gyro developed by Zimpher Technology and Shimmer Research was used 
TABLE 3: Specifications of some accelerometer ICs available.

\begin{tabular}{|c|c|c|c|c|}
\hline Accelerometer IC & Supply voltage & $\begin{array}{c}\text { Power } \\
\text { consumption }\end{array}$ & Full scale range & Bandwidth \\
\hline ADXL335 & $1.8 \mathrm{~V}-3.6 \mathrm{~V}$ & $350 \mu \mathrm{A}$ (typical) & $\pm 3 g$ & $\begin{array}{c}\text { For the } X \text {-and } \\
Y \text {-axes } 0.5 \mathrm{~Hz} \text { to } \\
1600 \mathrm{~Hz} \text { and for the } \\
Z \text {-axis } 0.5 \mathrm{~Hz} \text { to } \\
550 \mathrm{~Hz}\end{array}$ \\
\hline ADXL330 & $2.0 \mathrm{~V}-3.6 \mathrm{~V}$ & $\begin{array}{c}200 \mu \mathrm{A} \text { and } \mathrm{VS}= \\
2.0 \mathrm{~V} \text { (typical) }\end{array}$ & $\pm 3 \mathrm{~g}$ & $\begin{array}{c}\text { For } X \text {-and } Y \text {-axes } \\
0.5 \mathrm{~Hz} \text { to } 1,600 \mathrm{~Hz} \\
\text { and for the } Z \text {-axis } \\
0.5 \mathrm{~Hz} \text { to } 550 \mathrm{~Hz}\end{array}$ \\
\hline ADXL345 & $2.0 \mathrm{~V}-3.6 \mathrm{~V}$ & $\begin{array}{c}40 \mu \mathrm{A} \text { at } \mathrm{VS}=2.5 \mathrm{~V} \\
\text { (typical) }\end{array}$ & $\pm 16 \mathrm{~g}$ & \\
\hline SDI1221 & +5.0 and +2.5 volts & $\begin{array}{l}+5 \mathrm{VDC}, 8 \mathrm{~mA} \\
\text { power (typical) }\end{array}$ & $\pm 2 \mathrm{~g}$ & $0-400 \mathrm{~Hz}$ \\
\hline SCA3000 & $2.35 \mathrm{~V}-3.6 \mathrm{~V}$ & $2.5 \mathrm{~V}, 480 \mu \mathrm{A}$ typ & $\pm 2 \mathrm{~g}$ & $45 \mathrm{~Hz}$ (typical) \\
\hline LIS344ALH & $2.4 \mathrm{~V}-3.6 \mathrm{~V}$ & & $\pm 2 \mathrm{~g} / \pm 6 \mathrm{~g}$ & $1.8 \mathrm{kHz}$ for all axes \\
\hline MMA7260Q/MMA7260QT & $2.2 \mathrm{~V}-3.6 \mathrm{~V}$ & $500 \mu \mathrm{A}$ & $\pm 1.5 \mathrm{~g} / 2 \mathrm{~g} / 4 \mathrm{~g} / 6 \mathrm{~g}$ & $\begin{array}{c}350 \mathrm{~Hz} \text { for } X \& Y \\
\text { and } 150 \mathrm{~Hz} \text { for } Z\end{array}$ \\
\hline MMA8451Q & $1.95 \mathrm{~V}-3.6 \mathrm{~V}$ & $6 \mu \mathrm{A}$ to $165 \mu \mathrm{A}$ & $\pm 2 \mathrm{~g} / \pm 4 \mathrm{~g} / \pm 8 \mathrm{~g}$ & \\
\hline Bosch BMA180 & $\begin{array}{c}\mathrm{VDD}= \\
1.62 \mathrm{~V}-3.6 \mathrm{~V} \text { and } \\
\mathrm{VDDIO}= \\
1.2 \mathrm{~V}-3.6 \mathrm{~V}\end{array}$ & $650 \mu \mathrm{A}$ (typical) & $\begin{array}{c} \pm 1 \mathrm{~g}, \pm 1.5 \mathrm{~g}, \pm 2 \mathrm{~g} \\
\pm 3 \mathrm{~g}, \pm 4 \mathrm{~g}, \pm 8 \mathrm{~g} \\
\pm 16 \mathrm{~g}\end{array}$ & $\begin{array}{c}0.2 \mathrm{~Hz}-300 \mathrm{~Hz} \text { for } \\
\text { BPF }\end{array}$ \\
\hline
\end{tabular}

in [107]) means, heart rate [108], rotational velocity of foot [108], emotional eating (2-axis gyro was used), human posture and walking velocity (ENC03J developed by Murata Manufacturing Co. Ltd., Kyoto, Japan, was used in [18]), stride strength and walking velocity (ENV05S developed by Murata Manufacturing Co. Ltd., Kyoto, Japan, was used), muscle contractions (vibrating disc piezoelectric gyroscope was used in [19]), and motion processing in handsets (InvenSense MPU-3000 3-axis MEMS gyroscope was used).

The differences between gyroscope and accelerometer are given in Table 5 that help in the selection of gyroscope or accelerometer or both for ECG monitoring systems.

In order to differentiate the ECG signal due to heart activity from the patient's daily life activities, accelerometer and gyroscope alone are not sufficient. Therefore, it is suggested to use both accelerometer and gyroscope to find daily activities of patient effectively.

2.3. Placement of Electrodes. The placement of electrodes on the body varies based on type of wearable design. For different wearable types, placement of electrodes according to the previously proposed designs is given in Table 6 .

\subsection{Instrumentation Amplifier (IA)}

2.4.1. Mostly Used IA ICs. There are a number of instrumentation amplifier ICs available in the market suitable for ECG signal amplification. The use of IA in IC form is very easy and more convenient in ECG signal acquisition because of its small size and high noise immunity. The most widely used
IA ICs were developed by Texas Instruments and Analog Devices. Texas Instruments ICs INA116 [109, 110], INA121 [111], and INA128 [112] were most widely used in ECG signal acquisition systems. INA116 provided high input impedance $(1015 \Omega)$ and the bandwidth of $0.38-44 \mathrm{~Hz}( \pm 5 \%)$ with a single supply of $2 \mathrm{~V}$; it was used for long time ECG monitoring of athletes [109]. It was also used in the designing of low noise EEG/ECG sensor circuit [110]. INA121 with a two-input voltage buffer as driving Right Leg (RL) circuit provided differential gain $=1000$ from $0.05 \mathrm{~Hz}-100 \mathrm{~Hz}$ and commonmode gain $=0.06$ at power-line frequency $(50 \mathrm{~Hz})$ that results in $\mathrm{CMRR}=86 \mathrm{~dB}$ [111]. Analog devices ICs AD620 [113] and AD623 [114] were used for ECG signal acquisition and monitoring.

2.4.2. Circuit Designs of IA. Basically the instrumentation amplifier is designed using operational amplifier which acts as voltage amplifier [115] that provided gain $=54.83 \mathrm{~dB}$, CMRR $=141.61 \mathrm{~dB}$, and bandwidth $=223 \mathrm{~Hz}$ [55]. A simple unity-gain buffer stage and differential amplifier stage with high input impedance [116] were used to design IA to have optimised low-frequency response, low power, and CMRR. The minimum input resistance of the amplifier required was obtained as $1.3 \mathrm{M} \Omega$ [117]. A composite stabilised amplifier with active current feedback at its input stage was used to reduce amplifier saturation problems and baseline drift [118] in off-the-shelf ECG amplifier for a continuous long duration. But the amplitude is not matched with that of standard (3 electrodes) voltage ECG amplifier. If $\mathrm{RE}<50 \mathrm{k} \Omega$, the 
bandwidth of the circuit will decrease below the bandwidth of the acceptable limit. DDA (differential difference amplifier) was used to lower the power consumption and keep the open loop gain to enough value. The $\mathrm{AC}$ coupled technique was used to reduce offset noise. DDA with AC coupled technique [61] provided power supply rejection ratio $=62 \mathrm{~dB} \& \mathrm{CMRR}=$ $150 \mathrm{~dB}$ at $10 \mathrm{~Hz}$ and with the preferred input noise at $5 \mu \mathrm{V} / \mathrm{Hz}$ power consumption $=3.99 \mu \mathrm{W}$ at $1 \mathrm{~Hz}$. To remove offset voltage and reduce $1 / f$ noise, the low-frequency signal was to be eliminated. This was done by differential AC coupling network and the HP difference amplifier [119]. A design for remote electrocardiogram system, which consists of five stages ECG input, isolated amplifier, main amplifier, active BRF, and high order LPF with bandwidth $1 \mathrm{~Hz}-200 \mathrm{~Hz}$ [120], was used for ECG signal amplification and power supply $(60 \mathrm{~Hz})$ noise reduction.

Two-stage IA using operational transconductance amplifier (OTA) and common-mode feedback amplifier topology was used for common-mode amplifier noise reduction. This provided power consumption $=1.47 \mu \mathrm{W}$ and $\mathrm{CMRR}=82 \mathrm{~dB}$ [56]. An IA with series combination of two OTAs (one is preamplifier and second is variable-gain amplifier) provided power consumption $=233 \mathrm{nW}$, bandwidth $=21 \mathrm{~Hz}$, gain $=$ $44.2 \mathrm{~dB}$, and CMRR $=80 \mathrm{~dB}$ [60]. Flicker noise was removed by both chopper stabilised front end amplifier [121] and chopped capacitively coupled IA (CCIA) [122, 123]. Chopper technique which was implemented using folded cascode structure provided $36.44 \mathrm{~dB}$ of SNR in [54].

The instrumentation amplifier using the opamp for ECG signal acquisition cannot reduce noise much effectively. Therefore in order to solve this problem ECG amplifiers were designed using CMOS technology [56-63, 124-127] which also provide less power consumption and small area. The noise reduction in terms of CMRR obtained in different papers is mentioned in Table 7.

From Table 7, one can observe that most of the work reported was based on usage of same processing technology with different battery voltage. The work done in [62] was given better common-mode rejection ratio with a Monolithic CMOS current-mode instrumentation amplifier.

2.5. Filter. Filtering was required to remove the noise in ECG signal acquisition from electrodes followed by IA. The noise interferences were involved in many ways in ECG acquisition as its amplitude is less (in the order of $\mathrm{mV}$ ) and variability of ECG segments durations. Muscle contractions, electrode movements during acquisition, base line wandering, and $60 \mathrm{~Hz}$ power supply noise were some of the significant noise interferences. And also, filtering was required to separate the segment of interest from the acquired ECG signal like $\mathrm{P}$ wave, R-peak, QRS complex, T wave, and ST segment. Here removal of noise interference was not considered in this paper. Different filters and their frequency range for different parameters acquisition used by previously proposed authors are given in Table 8 for selecting and deigning of required filter.
From Table 8, it is shown that the most of the authors used LPF and HPF or BPF for measuring almost any parameter. But the frequency range is not the same for all. It is different for different parameters. Therefore, the designer has to select the frequency range based on his/her segment of interest.

2.6. ADC. The ADC ICs such as 16-bit, 100-kSPS SAR ADC ADS83212 [33], 10-bit SAR ADC [30, 38, 128], and 24-bit ADS1292 [129] were used for analog to digital conversion of signal. But nowadays the signal processing development boards like Texas products ADS1298, ADS1191, ADS1192, ADS1194, ADS1196, ADS1198, ADS1291, ADS1299, ADS1298R, ADS1296R, ADS1296, ADS1294R, ADS1294, ADS1293, and ADS1291 that provide analog voltage $2.7 \mathrm{~V}-$ $5.25 \mathrm{~V}$ and digital voltage $1.65 \mathrm{~V}$ to $3.6 \mathrm{~V}$ [130] and analog devices ADAS1000 (low power, 5-electrode ECG analog front end) and AD8232 (single-lead heart rate monitor analog front end) [131] are available with ADC inbuilt at significantly reduced size, power, and overall cost. Therefore, there is no need for external ADC to place.

2.7. Signal Processing Unit. Generally microcontroller board is used as signal processing unit to process the digital signal. This unit is further connected to PC/laptop to display the signals and measurements. It can also be used to communicate with other systems using transmitter and receiver. In previous designs proposed, for short term monitoring of ECG for $10 \mathrm{sec}$ or 1-2 minutes MSP430 microcontroller was used $[34,71]$ and for long-term monitoring TI CC2530 system [37], CC2431 [132], DSP [128], DSP chip TMS320VC5509A [133], TMS320F2812 [134], TMDX5505eZDsp/VC5505eZdsp [33], MSP430 (monitoring for 45 days) [68], MSP430F5515 [129], MSP430F1232 [43], MSP430FG439 [135], MSP430F2418 [136], MSP430F5529 [66] (monitoring for $88 \mathrm{~h}$ ) [39], MSP430F5419A (monitoring for $48 \mathrm{~h}$ ) [137], ATmega8 [41], ATmega328 [42], Arduino UNO (ATmega328) [47], ATmega8L [28, 31, 32], Concerto MCU [65], Revitive Device [27], PIC18LF4620 [69], Altera EP2C35 Nios II soft-core CPU based FPGA [138], ARM9 [139], ADuC842 [140], C8051F021 [141], 32-bit ARM Cortex M0 CPU (monitoring for $24 \mathrm{~h}$ ) [30], and STM32 chip as the system controller with ARM Cortex-M3 core (monitoring for $44 \mathrm{~h}$ ) [67] were used.

\subsection{Communication to PC/Laptop/Mobile Phone}

2.8.1. Need of Communication to PC/Laptop/Mobile Phone/Soc Network. After acquiring ECG signal, to display process and report the results of analysis to physician or doctor for diagnosis of the disease, there is a need for connecting to PC or Laptop. Mobile also can be used with specially designed apps.

\subsubsection{Available Communication Techniques}

(1) USB-SPI is generally used to connect the MC development board to PC. To display the signals and measurements MATLAB Simulink GUI or specially designed GUI is used. 
(2) Bluetooth is used for connecting to PC or mobile phone. To display the signals and measurements specially designed GUI is used in PC and for mobile phone (and also tablet) an android app is used. Motorola cell phone is providing an app developed with Java 2 Micro edition (J2ME).

(3) IEEE $80215.4 /$ ZigBee is used for PC connection. The signals can be displayed by using LabView or MATLAB GUI.

(4) WiFi is used for connecting to PC or mobile phone. With a specially designed GUI developed in Java, the signals can be displayed on PC and mobile phone. Open source software (the app is written in X-code using object C) developed by E.P. Ltd. is available in Apple's iPhone $4 \mathrm{~S}$ smartphone.

(5) GSM/GPRS/GPS is used for long distance monitoring of ECG by connecting with PC or mobile phone.

(6) Some of the system on chip (SoC) products like AT86RF212B, AT86RF233, AT86RF215, AT86RF215M, and AT86RF215IQ [142] will provide wireless communication network through ZigBee technology. TMS37157, TRF796X, TRF7970, AT86RF212, MCRF200, ADF7021, and ADF7025 [143] will provide communication using RFID technology. CC1101, CC1110, CC430, CC1190, CC11XL, CC112X, and CC120X [143] will provide communication using WPAN technology. CC2520, CC2530, CC2530ZNP, CC2531, CC2533, ADF4242, and AT86RF231 [143] will provide communication using ZigBee technology. CC2560, CC2540, CC2570, EM250, EM260, BCM4329, and BCM2045 [143] will provide communication using Bluetooth technology. WL1271, WL1281, BCM43241, BCM25/29, BCM4318, BCM4330, BCM4752, and AR6102 [143] will provide communication using WiFi technology. And WL1281, NL5500, UBX-G6010, BCM4750, and SiR starV [143] will provide communication using GPS technology.

2.8.3. Selection of Effective Communication Technique. The communication mode is selected based on the distance of monitoring the signals. For short distance wired connection like USB SPI or wireless communication (1 or up to $100 \mathrm{~m}$, depending on radio class) through Bluetooth or ZigBee technology (up to $75 \mathrm{~m}$ ) or WiFi (indoors about 150 feet $(46 \mathrm{~m})$ and outdoors about 300 feet $(92 \mathrm{~m})$ ) is generally preferred. For long distances GSM/GPRS (35 kilometres) or GPS (up to $25000 \mathrm{Km}$ ) is preferable. At present, all the communication technologies are inbuilt in the hardware and available as SoC (some of available SoC products are given in Section 2.8.2). When the SoC is selected for signal processing, it is better to select the suitable SoC product which is having preferred communication network technology. By providing long distance communication with the doctor, there is a scope for online monitoring of the patient condition and online diagnosis. This will not only save money and time, it will save lives of poor people. And also it helps to develop a smart city in the area of medical engineering.

\section{Discussion}

The death rate is increasing every year due to heart diseases from past few decades in India. This can be reduced by early detection of symptoms of abnormalities. A few years back, the ECG systems for detecting abnormalities were only available in the hospital and used only in the presence of specialists. It was very difficult to go every time to the hospital and take the ECG, which was also very expensive, especially for rural people. But present situation is slowly changing by using the health monitoring systems. Therefore, everything is going to change within few years in India like developed countries in the field of biomedicine by developing the smart and wearable health monitoring systems. So much of work is done by many people, but there is a lack of validation and communication provision with the doctor. There are options for recording and sending the data to the service centre where the data is analysed. But there is no accessibility of data to the user or patient. And also, they used commercial software which is licensed and very costly. Therefore, the net cost is very high.

In order to overcome these limitations and to add the missing features in existing systems, a new framework is proposed in this paper. In this review, quantitative information for designing of external cardiac loop recorder (ELR) is presented as a study of real-time ECG monitoring from remote area continuously. With the proper selection of the devices such as electrodes/sensors, instrumentation amplifier, filters, processor, and communication mode, an advanced external cardiac loop recorder is going to be designed to achieve better performance with less cost. New framework includes an option for saving the recorded ASCII data in text or excel form, and then it is easy to access and process the data. Further, the data can be processed and extract the features for detecting the normal or abnormal condition of the patient by using open source software called Scilab that reduces the cost of the system by avoiding commercial software used for analysis. And also by using open source software like TeraTerm, CoolTerm, and Processing with Arduino, data can be sent to a doctor via Bluetooth or Wi-Fi. Using Gobetwino open source software with Arduino data can be sent via the internet. Therefore, the doctor can receive and analyse the data using open source software and further he can send the suggestions or precautions to the patient at an early stage. If such a system is designed, it would become a milestone in the field of biomedical engineering and would help to develop the smart city towards the biomedical field in India. And also it will reach the rural people effectively so that the death rate due to heart diseases can be reduced.

It is evident from Tables 1-9 that one can design and configure appropriate internal circuitry components for the development of the cost effective external cardiac loop recorder system. The appropriate selection of open source software along with suitable internal circuitry will give way for new ELR suitable for implementation with less cost. Under a pilot process, a working prototype is under investigation by duly considering all the design parameters 
TABLE 4: Specifications of some gyro ICs.

\begin{tabular}{|c|c|c|c|}
\hline Ref. number & Gyro IC/sensor & Operating voltage & Axes \\
\hline$[17]$ & L3G4200D & $2.6 \mathrm{~V}-5.5 \mathrm{~V}$ & $\begin{array}{l} \pm 250(X), \pm 500(Y) \\
\quad \pm 2000^{\circ} / \mathrm{s}(Z)\end{array}$ \\
\hline$[18]$ & ENC03J & $2.7 \mathrm{~V}-5.5 \mathrm{~V}$ & $\operatorname{Max} \pm 300^{\circ} / \mathrm{s}$ \\
\hline [19] & ENV05S & $8-13.5 \mathrm{~V}$ & $\operatorname{Max} \pm 90^{\circ} / \mathrm{s}$ \\
\hline$[20]$ & Integrated Dual-Axis Gyro-IDG-300 & $3 \mathrm{~V}-3.5 \mathrm{~V}$ & $\begin{array}{c}\text { Full scale range of } \\
\pm 500^{\circ} / \mathrm{sec}\end{array}$ \\
\hline [21] & Integrated Dual-Axis Gyro-IDG-500 & $2.7 \mathrm{~V}-3.3 \mathrm{~V}$ & $\begin{array}{l}\text { Full scale range of } \\
\pm 500^{\circ} / \mathrm{sec}\end{array}$ \\
\hline [22] & Single Chip Rate Gyro EVAL-ADXRS610 & $4.75 \mathrm{~V}-5.25 \mathrm{~V}$ (typical $5 \mathrm{~V}$ ) & $\pm 300^{\circ} / \mathrm{sec}$ yaw rate \\
\hline [23] & SCC2000 Series Combined Gyro Sensor and Accelerometer & $3 \mathrm{~V}-3.6 \mathrm{~V}$ & $\begin{array}{c}X \text { - or } Z \text {-axis } \pm 125^{\circ} / \mathrm{s} \text { or } \\
\pm 300^{\circ} / \mathrm{s}\end{array}$ \\
\hline$[24]$ & $\mathrm{XV}-3500 \mathrm{CB} / \mathrm{XV} 3900 \mathrm{CB}$ & $3.3 \mathrm{~V}$ & $\pm 100^{\circ} / \mathrm{s}$ \\
\hline$[24]$ & $\mathrm{XV}-3510 \mathrm{CB}$ & $3.3 \mathrm{~V}$ & $\pm 300^{\circ} / \mathrm{s}$ \\
\hline$[24]$ & XV-3700CB & $3.3 \mathrm{~V}$ & $\pm 300^{\circ} / \mathrm{s}$ to $\pm 1500^{\circ} / \mathrm{s}$ \\
\hline$[24]$ & XV7011BB/XV7001BB & $2.7 \mathrm{~V}$ to $3.6 \mathrm{~V}$ & $\pm 100^{\circ} / \mathrm{s}$ \\
\hline$[24]$ & AH-6120LR & $3 \mathrm{~V}$ & $\pm 1000^{\circ} / \mathrm{s}$ \\
\hline [24] & AP-6110LR & $2.85 \mathrm{~V}$ to $3.6 \mathrm{~V}$ & $\pm 300^{\circ} / \mathrm{s}$ \\
\hline
\end{tabular}

TABLE 5: Differences between gyroscope and accelerometer.

\begin{tabular}{|c|c|c|}
\hline S. number & Gyroscope & Accelerometer \\
\hline 1 & It determines orientation & $\begin{array}{l}\text { It measures static (e.g., gravity) as well as dynamic (e.g., } \\
\text { sudden starts/stops) acceleration }\end{array}$ \\
\hline 2 & Senses rotation & Cannot sense rotation \\
\hline 3 & $\begin{array}{l}\text { It measures the rotation rate around } \\
\text { a particular axis based on } \\
\text { angular momentum }\end{array}$ & It measures linear acceleration based on vibration \\
\hline 4 & A gyroscope is used to determine angular position & $\begin{array}{l}\text { Two-axis accelerometer is used to determine the direction } \\
\text { of gravity }\end{array}$ \\
\hline 5 & $\begin{array}{l}\text { Applications: in navigation on unmanned aerial vehicles, } \\
\text { compasses and large boats, ultimately assisting with } \\
\text { stability in navigation, and altitude; indicator on typical } \\
\text { aircraft }\end{array}$ & $\begin{array}{l}\text { Applications: determines screen orientation and acts as a } \\
\text { compass undoing actions by simply shaking the } \\
\text { smartphone }\end{array}$ \\
\hline 6 & $\begin{array}{l}\text { Gyroscopes are used in extra earth navigation (spacecraft), } \\
\text { where the planet earth's pull and influence disappear }\end{array}$ & $\begin{array}{l}\text { 3-axis accelerometer could identify the orientation of an } \\
\text { object relative to the Earth's surface }\end{array}$ \\
\hline
\end{tabular}

TABLE 6: Electrode placement for different type of wearable.

\begin{tabular}{|c|c|c|c|c|}
\hline Ref. paper & Wearable type & Number of electrodes & Type of electrodes & Placement of electrodes \\
\hline$[25]$ & Tight fitted sleeveless top & - & Dry Ag/AgCl electrode & Chest line \\
\hline$[26]$ & $\begin{array}{c}\text { Wearable } \\
\text { (vital jacket system) }\end{array}$ & - & - & On chest \\
\hline [27] & BioShirt & 3 & $\begin{array}{l}3 \mathrm{M} \mathrm{Ag} / \mathrm{AgCl} 2223 \text { monitoring } \\
\text { electrode which has foam tape } \\
\text { and sticky gel }\end{array}$ & $\begin{array}{c}\text { ECG limb leads and augmented } \\
\text { unipolar limb leads }\end{array}$ \\
\hline [28] & Belt type & 2 & ECG & $\begin{array}{c}\text { RA-LA } 11 \mathrm{~cm} \text { apart through midline on } \\
\text { chest }\end{array}$ \\
\hline$[29]$ & Wearable belt & 4 & ECG & $\begin{array}{c}\text { Channel } 1(+) \text {, in the fifth intercostal } \\
\text { space in anterior axillary line. Channel } \\
1(-) \text {, manubrium of sternum on the } \\
\text { right side. } \\
\text { Channel } 2(+) \text {, on sternum on the same } \\
\text { altitude as the fourth intercostal space. } \\
\text { Channel } 2(-) \text {, left subclavian area. } \\
\text { Ground: in the fifth intercostal space } \\
\text { in midaxillary line }\end{array}$ \\
\hline
\end{tabular}


TABLE 6: Continued.

\begin{tabular}{|c|c|c|c|c|}
\hline Ref. paper & Wearable type & Number of electrodes & Type of electrodes & Placement of electrodes \\
\hline$[30]$ & Wearable chest harness & - & Coin sized dry-contact electrodes & On chest \\
\hline$[31]$ & Wearable chest belt & 2 & ECG & On chest \\
\hline$[32]$ & Chest belt & 2 & & On chest \\
\hline [33] & Wearable ECG vest & 3 & $\mathrm{Ag}-\mathrm{AgCl}$ & $\begin{array}{l}\text { Three Velcro tapes in neck, back, and } \\
\text { waist }\end{array}$ \\
\hline$[34]$ & Wearable & 3 & $\mathrm{Ag} / \mathrm{AgCl}$ & LA, RA, RF \\
\hline [35] & Wearable & 3 & & $\begin{array}{l}\text { RA-LA } 5 \mathrm{~cm} \text { through midline and } \\
\text { LL-LA end to center of LL } 6 \mathrm{~cm} \text { down }\end{array}$ \\
\hline$[36]$ & Wearable & 3 & & Einthoven triangle \\
\hline$[37]$ & & 3 & ECG & $\begin{array}{l}\text { RA-RL-LA placed b/w midline \& } \\
\text { distance RA-LA is } 5 \mathrm{~cm} \text {. LL is } 5 \mathrm{~cm} \\
\text { down from RA-LA line and } 5 \mathrm{~cm} \text { left } \\
\text { from midline }\end{array}$ \\
\hline$[38]$ & - & - & - & $\begin{array}{c}\text { Sensors on the lumbar support } \\
\text { cushion of the seat }\end{array}$ \\
\hline$[39]$ & - & 10 & - & Standard positions to generate 12 leads \\
\hline$[40]$ & - & 3 & - & Einthoven triangle \\
\hline$[41]$ & - & 3 & ECG & RA-LA-RL \\
\hline$[42]$ & - & - & Dry clamp electrodes & Located on the wrists \\
\hline$[43]$ & - & 2 & Capacitive coupling electrodes & $\begin{array}{c}\text { On chest } \\
\text { lead I }\end{array}$ \\
\hline$[44]$ & - & 12 & - & 12-lead ECG system \\
\hline$[45]$ & - & - & $\begin{array}{l}\text { QUASAR's capacitive bioelectrodes } \\
\text { (can measure with clothes) }\end{array}$ & $\begin{array}{l}\text { Integrated into a pad system that is } \\
\text { placed over a chair }\end{array}$ \\
\hline$[46]$ & - & 12 & - & 12-lead standard placement \\
\hline$[47]$ & - & 3 & - & Einthoven triangle \\
\hline$[48]$ & - & - & Patch-type electrode & On chest \\
\hline [49] & - & 12 & - & 12-lead standard placement \\
\hline$[50]$ & - & - & $\begin{array}{c}\text { Wet gel Ag/AgCl electrodes (Ambu, } \\
\text { Blue Sensor R) }\end{array}$ & Below the left pectoral muscle \\
\hline [51] & - & 3 & - & (RA, LA, RL), lead II \\
\hline$[52]$ & Not wearable & 3 & - & $\begin{array}{l}\text { LA, RA, LF (separated by } 10 \mathrm{~cm} \text { ) and } \\
\text { an extra electrode placed on RL (forms } \\
\text { an equilateral triangle) }\end{array}$ \\
\hline [53] & Not wearable & 4 & - & RA, LA, LL, RL \\
\hline
\end{tabular}

TABLE 7: CMRR comparison of different works done for ECG amplifier using CMOS technology.

\begin{tabular}{lccc}
\hline Reference paper & CMRR & Process tech & Battery voltage \\
\hline$[54]$ & $71 \mathrm{~dB}$ & $0.18 \mu \mathrm{m}$ & $1.8 \mathrm{~V}$ dual \\
{$[55]$} & $141.61 \mathrm{~dB}$ & $0.18 \mu \mathrm{m}$ & $1.8 \mathrm{~V}$ dual \\
{$[56]$} & $82 \mathrm{~dB}$ & $0.18 \mu \mathrm{m}$ & - \\
{$[57]$} & $>125 \mathrm{~dB}$ & $0.18 \mu \mathrm{m}$ & $0.4 \mathrm{~V}$ \\
{$[58]$} & $62 \mathrm{~dB}$ & - & $3.3 \mathrm{~V}$ \\
{$[59]$} & $>100 \mathrm{~dB}$ & - & $3.3 \mathrm{~V}$ \\
{$[60]$} & $80 \mathrm{~dB}$ & $0.13 \mu \mathrm{m}$ & $0.7 \mathrm{~V}$ \\
{$[61]$} & $150 \mathrm{~dB}$ & $0.18 \mu \mathrm{m}$ & $1.8 \mathrm{~V}$ \\
{$[62]$} & $167.87 \mathrm{~dB}$ & - & - \\
{$[63]$} & $125 \mathrm{~dB}$ & $0.18 \mu \mathrm{m}$ & - \\
\hline
\end{tabular}

and software requirements. This expected design system will ensure the required diagnostic precision suitable for detecting the cardiac episodes.

\section{Conclusion}

This research study provided an insight into the systematic review on external cardiac loop recorders. It gives the quantitative information which helps in the selection of internal parts of the external cardiac loop recorder. Although several techniques for monitoring cardiac episodes were available, the scope for a new cardiac device is still in demand. This is due to the fact that the real-time cardiac episodes monitoring and its corresponding alert mechanism can help in saving the life of the patient. Such mechanism through the advent of cost 
TABLE 8: Filters and their frequency range for various ECG parameters.

\begin{tabular}{|c|c|c|c|}
\hline Ref. number & Parameters acquired & Filter used & Freq range \\
\hline$[64]$ & Heart rate & Bandpass filter & - \\
\hline$[30]$ & Heart rate & Passive RC high pass filter & $1 \mathrm{~Hz}$ \\
\hline [31] & Heart rate & LPF, after IA notch, HPF, LPF & $\begin{array}{l}F_{\mathrm{lpf}}=150 \mathrm{~Hz}, F_{n}=60 \mathrm{~Hz} \\
F_{\mathrm{hpf}}=0.5 \mathrm{~Hz}, F_{\mathrm{lpf}}=35 \mathrm{~Hz}\end{array}$ \\
\hline [65] & Heart rate & LPF & $F_{\mathrm{lpf}}=40-80 \mathrm{~Hz}$ \\
\hline [45] & Heart rate & 8-pole Bessel bandpass filter & $0.1-100 \mathrm{~Hz}$ \\
\hline [37] & QRS complexes, heart rate & BPF & \\
\hline$[28]$ & R-peak, heart rate & HPF, 2nd-order Butterworth filter (two 1st-order LPF) & $\begin{array}{c}F_{h}=0.05 \mathrm{~Hz} \\
F_{L}=35 \mathrm{~Hz}\end{array}$ \\
\hline [32] & R-peak, abnormal heart beat & LPF, moving average filter & $F_{\mathrm{lpf}}=35 \mathrm{~Hz}$ \\
\hline$[66]$ & ECG and heart rate & Notch filter formed by ordinary amplifier TL062 & $F_{c}=50 \mathrm{~Hz}$ \\
\hline [38] & ECG wave, R-peak & $\mathrm{LPF}, \mathrm{BPF}$ & $F_{\mathrm{bpf}}=5-20 \mathrm{~Hz}$ \\
\hline [67] & R-peaks & LPF, HPF & \\
\hline [44] & R-peak & Adaptive filter & \\
\hline [68] & $\mathrm{Pk}-\mathrm{Pk}$ & Analog active RC filter, a second-order Butterworth & \\
\hline [29] & HRV & LPF & \\
\hline$[42]$ & ECG, PPG, BP & HPF, LPF & $F_{h}=0.16 \mathrm{~Hz}, F_{l}=103 \mathrm{~Hz}$ \\
\hline [69] & QRS complex & Antialiasing 1-pole LPF & $F_{l}=35 \mathrm{~Hz}$ \\
\hline$[70]$ & QRS, T wave & HPF, sixth-order Bessel LPF & $F_{\mathrm{lpf}}=150 \mathrm{~Hz}$ \\
\hline$[50]$ & QRS complexes and $\mathrm{T}$ waves & RC high pass filters & $F_{3-\mathrm{dB}}=0.16 \mathrm{~Hz}$ \\
\hline [71] & PQRST wave & Bandpass filter & $0.159-159 \mathrm{~Hz}$ \\
\hline [72] & Points (P, Q, R, S, T) & BPF, notch filter & $F_{\mathrm{bpf}}=0.05 \mathrm{~Hz}$ to $150 \mathrm{~Hz}, F_{n}=6 \mathrm{~Hz}$ \\
\hline$[51]$ & $\begin{array}{l}\text { QRS duration, RR interval, HBR, } \\
\text { R amplitude, RT-interval: } \\
\text { PR-interval: QT-interval features }\end{array}$ & LPF, HPF, LPF & $\begin{array}{c}F_{\mathrm{lpf}}=0.03 \mathrm{~Hz} \\
F_{\mathrm{hpf}}=80 \mathrm{~Hz} \\
F_{\mathrm{lpf}}=58 \mathrm{~Hz} \text { and } 19 \mathrm{~Hz}\end{array}$ \\
\hline
\end{tabular}

TABLE 9: Different microcontrollers used for ECG monitoring.

\begin{tabular}{|c|c|c|c|}
\hline MP or MC used & Supply voltage range & Max power consumption & Memory storage \\
\hline MSP430 & $2.5 \mathrm{~V}$ to $5.5 \mathrm{~V}$ & $330 \mu \mathrm{A}$ at $1 \mathrm{MHz}, 3 \mathrm{~V}$ & 2 k byte ROM, 128-byte RAM \\
\hline MSP430F5529 & $1.8 \mathrm{~V}$ to $3.6 \mathrm{~V}$ & $290 \mu \mathrm{A}$ at $8 \mathrm{MHz}, 3.0 \mathrm{~V}$ & $128 \mathrm{~KB}$ flash $\& 8 \times 2 \mathrm{~KB}$ SRAM \\
\hline MSP430F5419A & $1.8 \mathrm{~V}$ to $3.6 \mathrm{~V}$ & $230 \mu \mathrm{A}$ at $8 \mathrm{MHz}, 3.0 \mathrm{~V}$ & $128 \mathrm{~KB}$ flash \& $16 \mathrm{~KB}$ SRAM \\
\hline MSP430F5515 & $1.8 \mathrm{~V}$ to $3.6 \mathrm{~V}$ & $290 \mu \mathrm{A}$ at $8 \mathrm{MHz}, 3.0 \mathrm{~V}$ & $64 \mathrm{~KB}$ flash $\& 4 \times 2 \mathrm{~KB}$ SRAM \\
\hline MSP430 (F2) & $1.8 \mathrm{~V}$ to $3.6 \mathrm{~V}$ & $220 \mu \mathrm{A}$ at $1 \mathrm{MHz}, 2.2 \mathrm{~V}$ & $1 \mathrm{~KB}+256 \mathrm{~B}$ flash memory $128 \mathrm{~B}$ RAM \\
\hline MSP430F1232 & $1.8 \mathrm{~V}-3.6 \mathrm{~V}$ & $200 \mu \mathrm{A}$ at $1 \mathrm{MHz}, 2.2 \mathrm{~V}$ & $8 \mathrm{~KB}+256 \mathrm{~B}$ flash memory, $256 \mathrm{~B}$ RAM \\
\hline MSP430FG439 & $1.8 \mathrm{~V}$ to $3.6 \mathrm{~V}$ & $300 \mu \mathrm{A}$ at $1 \mathrm{MHz}, 2.2 \mathrm{~V}$ & $60 \mathrm{~KB}+256 \mathrm{~B}$ flash memory, $2 \mathrm{~KB}$ RAM \\
\hline MSP430F2418 & $1.8 \mathrm{~V}$ to $3.6 \mathrm{~V}$ & $365 \mu \mathrm{A}$ at $1 \mathrm{MHz}, 2.2 \mathrm{~V}$ & $116 \mathrm{~KB}+256 \mathrm{~B}$ flash memory, $8 \mathrm{~KB}$ RAM \\
\hline TI CC2530 & $2 \mathrm{~V}-3.6 \mathrm{~V}$ & $29 \mathrm{~mA}$ at $2.4 \mathrm{GHz}$ & $32 \mathrm{~KB}$ flash \& $8 \mathrm{~KB}$ RAM \\
\hline TI CC2431 & $2 \mathrm{~V}-3.6 \mathrm{~V}$ & $27 \mathrm{~mA}$ at $32 \mathrm{MHz}$ & $128 \mathrm{~KB}$ flash \& 8 KB RAM \\
\hline TMS320VC5509A & $2.7-\mathrm{V}-3.6-\mathrm{V}$ & - & $\begin{array}{c}128 \mathrm{~K} \times 16 \text {-bit on-chip RAM, } 64 \mathrm{~K} \text { bytes one wait } \\
\text { state on-chip ROM, } 16 \mathrm{MB} \text { DRAM }\end{array}$ \\
\hline TMS320F2812 & $1.8 \mathrm{~V}-3.3 \mathrm{~V}$ & 1.9-V Core at $150 \mathrm{MHz}$ & $128 \mathrm{~K} \times 16$ flash, $128 \mathrm{~K} \times 16 \mathrm{ROM}$ \\
\hline $\begin{array}{l}\text { TMDX5505eZDsp/ } \\
\text { VC5505eZdsp }\end{array}$ & $1.8 \mathrm{~V}, 2.5 \mathrm{~V}, 2.8 \mathrm{~V}, 3.3 \mathrm{~V}$ & - & $320 \mathrm{~KB}$ of on-chip RAM, $128 \mathrm{~KB}$ of on-chip ROM \\
\hline ATmega8 & $4.5 \mathrm{~V}-5.5 \mathrm{~V}$ & $3.6 \mathrm{~mA}$ at $4 \mathrm{MHz}, 3 \mathrm{~V}, 25^{\circ} \mathrm{C}$ & 8 KB flash, 512 B EEPROM, 1 KB SRAM \\
\hline ATmega8L & $2.7 \mathrm{~V}-5.5 \mathrm{~V}$ & $3.6 \mathrm{~mA}$ at $4 \mathrm{MHz}, 3 \mathrm{~V}, 25^{\circ} \mathrm{C}$ & 8 KB flash, 512 B EEPROM, 1 KB SRAM \\
\hline ATmega328 & $1.8-5.5 \mathrm{~V}$ & $0.2 \mathrm{~mA}$ at $1 \mathrm{MHz}, 1.8 \mathrm{~V}, 25^{\circ} \mathrm{C}$ & $32 \mathrm{~KB}$ of flash, $1 \mathrm{~K}$ byte EEPROM, $2 \mathrm{~KB}$ of SRAM \\
\hline $\begin{array}{l}\text { Arduino } \\
\text { (ATmega328) }\end{array}$ & $5 \mathrm{~V}$ & - & $32 \mathrm{~KB}$ of flash, $1 \mathrm{~K}$ byte EEPROM, $2 \mathrm{~KB}$ of SRAM \\
\hline $\begin{array}{l}\text { Concerto MCU } \\
\text { (MB95F108AHS) }\end{array}$ & $5 \mathrm{~V}$ & - & $60 \mathrm{~KB}$ dual-flash, 2 KB RAM \\
\hline PIC18LF4620 & $2.0 \mathrm{~V}$ to $5.5 \mathrm{~V}$ & - & 64 KB flash, 3968 SRAM, 1024 EEROM \\
\hline $\mathrm{ADuC} 842$ & - & $4.5 \mathrm{~mA}$ at $3 \mathrm{~V}($ core $\mathrm{CLK}=2.098 \mathrm{MHz})$ & 64 KB flash, 2 KB SRAM \\
\hline C8051F021 & $2.7 \mathrm{~V}-3.6 \mathrm{~V}$ & - & $4.25 \mathrm{~KB}$ RAM, $64 \mathrm{~KB}$ ROM \\
\hline $\begin{array}{l}\text { 32-bit ARM cortex } \\
\text { M0 CPU }\end{array}$ & - & $64.3 \mu \mathrm{W} / \mathrm{MHz}$ & - \\
\hline
\end{tabular}


effecting wearable external cardiac loop recorder will provide a major healthcare revolution in the developing countries.

\section{Competing Interests}

The authors declare that they have no competing interests.

\section{References}

[1] P. Zimetbaum and A. Goldman, "Ambulatory arrhythmia monitoring," American Heart Association, Circulation, vol. 122, pp. 1629-1636, 2010.

[2] http://www.heart.org/HEARTORG/Conditions/HeartAttack/ SymptomsDiagnosisofHeartAttack/Holter-Monitor_UCM_ 446437_Article.jsp\#.V_o8kk-LXnM.

[3] http://stuccu.com/s/Holter+Monitor-MbSLsTI-Buy-ExclusiveDeals-70-OFF-Save-Big-Lowest-Price-on-Holter-Monitor.

[4] http://www.medhelp.org/posts/Heart-Rhythm/Cost-for-holtormonitor/show/1630319.

[5] http://wwwp.medtronic.com/Newsroom/LinkedItemDetails .do?itemId=1160041295600\%20\&\%20format=pdf\%20\&lang= en_IN.

[6] A. D. Krahn, G. J. Klein, R. Yee, J. S. Hoch, and A. C. Skanes, "Cost implications of testing strategy in patients with syncope: randomized assessment of syncope trial," Journal of the American College of Cardiology, vol. 42, no. 3, pp. 495-501, 2003.

[7] http://www.ispor.org/ScientificPresentationsDatabase/Presentation/54447.

[8] R. Subbiah, P.-L. Chia, L. J. Gula et al., "Cardiac monitoring in patients with syncope: making that elusive diagnosis," Current Cardiology Reviews, vol. 9, no. 4, pp. 299-307, 2013.

[9] C. Nachane, D. Subramanian, J. Warrier, and V. Sinha, "Development of acquisition of ECG during treadmill exercise," International Journal of Scientific \& Engineering Research, vol. 6, no. 4, pp. 1285-1288, 2015.

[10] M. Brignole, P. Vardas, E. Hoffman et al., "Indications for the use of diagnostic implantable and external ECG loop recorders," Europace, vol. 11, no. 5, pp. 671-687, 2009.

[11] http://www3.gehealthcare.co.uk.

[12] http://www3.gehealthcare.pl/ /media/downloads/uk/product/ diagnostic\%20ecg/ambulatory/seer1000/dcar_emea_brochure_ seer_1000_with_cardioday_english_doc1286154_rev2_11-2013.pdf? Parent=\%7BF194EDD5-D167-469C-B6A3-E21B8ABE8393\%7D.

[13] http://www.medtronicdiagnostics.com.

[14] http://www.vicare-medical.dk/admin/UploadFile.aspx?path=/ UserUploadFiles/Monitorering/Corventis\%20Event\%20recorder/ Nuvant_Spec.pdf.

[15] http://omronhealthcare.com.au/pdf2/HCG-801_Brochure.pdf.

[16] http://www.mrisafety.com/SafetyInfov.asp?SafetyInfoID=249.

[17] S. Tanaka, K. Motoi, M. Nogawa, and K. Yamakoshi, "A new portable device for ambulatory monitoring of human posture and walking velocity using miniature accelerometers and gyroscope," in Proceedings of the 26th Annual International Conference of the IEEE Engineering in Medicine and Biology Society (EMBC '04), pp. 2283-2286, San Francisco, Calif, USA, September 2004.

[18] S. Tanaka, K. Motoi, M. Nogawa, and K. Yamakoshi, "A new portable device for ambulatory monitoring of human posture and walking velocity using miniature accelerometers and gyroscope," in Proceedings of the 26th Annual International
Conference of the IEEE Engineering in Medicine and Biology Society (EMBC '04), pp. 2283-2286, September 2004.

[19] A. K. Singh and U. K. Gorain, "Development of vibrating disc piezoelectric gyroscope," Defence Science Journal, vol. 54, no. 3, pp. 387-393, 2004.

[20] https://www.sparkfun.com/datasheets/Components/IDG-300_ Datasheet.pdf.

[21] https://www.sparkfun.com/datasheets/Components/SMD/Datasheet_IDG500.pdf.

[22] http://www.analog.com/media/en/technical-documentation/ data-sheets/ADXRS610.pdf.

[23] http://www.murata.com/en-eu/products/sensor/gyro/scc2000.

[24] http://www5.epsondevice.com/en/products/standard_gyro/.

[25] H. Cho and J. H. Lee, "A study on the optimal positions of ECG electrodes in a garment for the design of ECG-monitoring clothing for male," Journal of Medical Systems, vol. 39, article 95, 2015.

[26] K. Zhang, L. Song, and D. Lu, "Design of remote ECG monitoring system based on GPRS," in Proceedings of the 2011 International Conference on Computer Science and Network Technology (ICCSNT '11), pp. 319-322, Harbin, China, December 2011.

[27] Y. Jang, H. W. Noh, I. B. Lee, and Y. Song, "A basic study for patch type ambulatory 3-electrode ECG monitoring system for the analysis of acceleration signal and the limb leads and augmented unipolar limb leads signal," in Proceedings of the 32nd Annual International Conference of the IEEE EMBS, pp. 3864-3867, Buenos Aires, Argentina, 2010.

[28] B.-H. Kim, Y.-H. Noh, and D.-U. Jeong, "A wearable ECG monitoring system using adaptive EMD filter based on activity status," in Proceedings of the 29th IEEE International Conference on Advanced Information Networking and Applications Workshops (WAINA '15), pp. 11-16, Gwangju, South Korea, March 2015.

[29] A. A. Altun and N. Başçıfcı, "A wireless sensor network based on zigbee for ECG monitoring system," in Proceedings of the 5th International Conference on Application of Information and Communication Technologies (AICT '11), IEEE, Baku, Azerbaijan, October 2011.

[30] E. Valchinov, A. Antoniou, K. Rotas, and N. Pallikarakis, "Wearable ECG system for health and sports monitoring," in Proceedings of the 4th International Conference on Wireless Mobile Communication \& Healthcare (MOBIHEALTH '14), pp. 63-66, November 2014.

[31] J. H. Yap and D. U. Jeong, "Design and implementation of ubiquitous ECG monitoring system by using android tablet," in Ubiquitous Information Technologies and Applications, vol. 214 of Lecture Notes in Electrical Engineering, pp. 269-277, Springer, Berlin, Germany, 2013.

[32] Y.-H. Noh, Y. J. Huei, and D.-U. Jeong, "Implementation of the abnormal ECG monitoring system using heartbeat check map thechnique," in Proceedings of the 2013 3rd International Conference on IT Convergence and Security (ICITCS '13), Macau, December 2013.

[33] W. Weiya, G. Li, L. Zhanfeng, and H. Gui, "Research on wearable EeG monitoring system based on ZigBee," in Proceedings of the IEEE Cross Strait Quad-Regional Radio Science and Wireless Technology Conference, pp. 929-932, 2011.

[34] M.-C. Rosu, "Implementation for a WBAN-ECG monitoring system (Preliminary results)," in Proceedings of the IEEE International Conference on Optimization of Electrical and Electronic Equipment (OPTIM '14), pp. 823-826, Bran, Romania, May 2014. 
[35] Y. Wang, R. Wunderlich, and S. Heinen, "Design and evaluation of a novel wireless reconstructed 3-lead ECG monitoring system," in Proceedings of the IEEE Biomedical Circuits and Systems Conference (BioCAS '13), pp. 362-365, IEEE, Rotterdam, The Netherlands, November 2013.

[36] A. Acharyya, K. Maharatna, B. M. Al-Hashimi, and H. Tudugalle, "Simplified logic design methodology for fuzzy membership function based robust detection of maternal modulus maxima location: a low complexity Fetal ECG extraction architecture for mobile health monitoring systems," in Proceedings of the IEEE International Symposium on Circuits and Systems (ISCAS '11), pp. 77-80, Rio de Janeiro, Brazil, May 2011.

[37] Y. Wang, S. Doleschel, R. Wunderlich, and S. Heinen, "A wearable wireless ECG monitoring system with dynamic transmission power control for long-term homecare," Journal of Medical Systems, vol. 39, no. 3, 2015.

[38] J. Son, B. Kim, and M. Park, "Lumbar cushion based realtime ECG sensing system for monitoring driver's state," in Proceedings of the IEEE International Conference on Consumer Electronics (ICCE '15), pp. 261-262, Las Vegas, Nev, USA, January 2015.

[39] J. E. Gaxiola-Sosa, N. Mohsin, A. J. Palliyali, R. Tafreshi, and K. Entesari, "A portable 12-lead ECG wireless medical system for continuous cardiac-activity monitoring," in Proceedings of the 2nd Middle East Conference on Biomedical Engineering (MECBME '14), pp. 123-126, IEEE, Doha, Qatar, February 2014.

[40] M. Hadjem, O. Salem, and F. Naït-Abdesselam, "An ECG monitoring system for prediction of cardiac anomalies using WBAN," in Proceedings of the 16th IEEE International Conference on e-Health Networking, Applications and Services (Healthcom '14), pp. 441-446, Natal, Brazil, October 2014.

[41] D. J. Harmah and D. Kathirvelu, "An ubiquitous miniaturized android based ECG monitoring system," in Proceedings of the IEEE International Conference on Emerging Trends in Computing, Communication and Nanotechnology (ICE-CCN '13), pp. 117-120, Tirunelveli, India, March 2013.

[42] J. Martinho, L. Prates, and J. Costa, "Design and implementation of a wireless multiparameter patient monitoring system," Procedia Technology, vol. 17, pp. 542-549, 2014.

[43] Z. Ping, L. Zhoucheng, W. Feng, and J. Hongyu, "Non-contact ECG monitoring based on capacitive electrodes. springer, world congress on medical physics and biomedical engineering," in World Congress on Medical Physics and Biomedical Engineering May 26-31, 2012, Beijing, China, vol. 39 of IFMBE Proceedings, pp. 1506-1509, Springer, Berlin, Germany, 2013.

[44] Z. Tse, C. Dumoulin, G. Clifford et al., "Cardiac MRI with concurrent physiological monitoring using MRI-compatible 12lead ECG," Journal of Cardiovascular Magnetic Resonance, vol. 14, supplement 1, article P231, 2012.

[45] N. J. McDonald, H. A. Anumula, E. Duff, and W. Soussou, "Noncontact ECG system for unobtrusive long-term monitoring," in Proceedings of the 34th Annual International Conference of the IEEE Engineering in Medicine and Biology Society (EMBS '12), pp. 1614-1618, Boston, Mass, USA, September 2012.

[46] T. Chen, E. Mazomenos, K. Maharatna, S. Dasmahapatra, and M. Niranjan, "On the trade-off of accuracy and computational complexity for classifying normal and abnormal ECG in remote CVD monitoring systems," in Proceedings of the IEEE Workshop on Signal Processing Systems (SiPS '12), pp. 37-42, IEEE, Quebec, Canada, October 2012.

[47] P. Juan Pablo Tello, O. Manjarres, M. Quijano, and A. Ulises Blanco, "Remote monitoring system of ECG and temperature signals using Bluetooth," in Proceedings of the IEEE International Symposium on Information Technologies in Medicine and Education (ITME '12), pp. 860-863, Hakodate, Japan, August 2012.

[48] H. Fernández-López, J. H. Correia, R. Simões, and J. A. Afonso, "Experimental evaluation of IEEE 802.15.4/ZigBee for multipatient ECG monitoring," in Electronic Healthcare, vol. 69 of Lecture Notes of the Institute for Computer Sciences, Social Informatics and Telecommunications Engineering, pp. 184-191, Springer, 2011.

[49] M. Smoleń, P. Kańtoch, P. Augustyniak, and P. Kowalski, "Wearable patient home monitoring based on ECG and ACC sensors," in 5th European Conference of the International Federation for Medical and Biological Engineering, vol. 37 of IFMBE Proceedings, pp. 941-944, Springer, 2012.

[50] J. Lekkala, T. Salpavaara, J. Verho, and J. Riistama, "Simple inductively coupled resonance sensor for ECG and heart rate monitoring," Procedia Engineering, vol. 5, pp. 1438-1441, 2010.

[51] G. Gupta, "PC based ECG monitoring system," in Proceedings of the 2nd International Conference on Advances in Recent Technologies in Communication and Computing (ARTCom '10), pp. 348-350, Kottayam, India, October 2010.

[52] M. S. Kim, Y. C. Cho, S.-T. Seo, C.-S. Son, and Y.-N. Kim, "Autodetection of R wave in ECG (electrocardiography) for patchtype ECG remote monitoring system," Biomedical Engineering Letters, vol. 1, no. 3, pp. 180-187, 2011.

[53] A. Loewe, W. H. W. Schulze, Y. Jiang, M. Wilhelms, and O. Dössel, "Determination of optimal electrode positions of a wearable ECG monitoring system for detection of myocardial ischemia: a simulation study," Computing in Cardiology, vol. 38, pp. 741-744, 2011.

[54] J. G. Lau and A. B. Marzuki, "A low power low noise CMOS amplifier for portable ECG monitoring application," $A R P N$ Journal of Engineering and Applied Sciences, vol. 9, no. 12, pp. 2448-2453, 2014.

[55] J. Dangi and R. C. Gurjar, "An Ecg instrumentation amplifier with improved Cmrr and gain using. $18 \mu \mathrm{m}$ technology," in Proceedings of the 11th IRF International Conference, pp. 92-95, Pune, India, October 2015.

[56] D. J. Moni and N. Gopalakrishnan, "A low power CMOS electrocardiogram amplifier design using $0.18 \mu \mathrm{m}$ CMOS technology," International Journal of Advancements in Research \& Technology, vol. 2, no. 2, pp. 1-5, 2013.

[57] Y. Tseng, Y. Ho, S. Kao, and C. Su, "A 0.09 W low power front-end biopotential amplifier for biosignal recording," IEEE Transactions on Biomedical Circuits and Systems, vol. 6, no. 5, pp. 508-516, 2012.

[58] M. Y. Ren, C. X. Zhang, and D. S. Sun, "Design of CMOS instrumentation amplifier," in Proceedings of the 2012 International Workshop on Information and Electronics Engineering (IWIEE '12), vol. 29, pp. 4035-4039, Harbin, China, March 2012.

[59] L. Xiu and Z. Li, "Low-power instrumentation amplifier IC design for ECG system applications," in Proceedings of the International Workshop on Information and Electronics Engineering (IWIEE '12), vol. 29, pp. 1533-1538, Harbin, China, March 2012.

[60] J.-Y. Um, J.-Y. Sim, and H.-J. Park, "A gate-leakage insensitive 0.7-V 233-nW ECG amplifier using non-feedback PMOS pseudo-resistors in $0.13-\mu \mathrm{m} \mathrm{N}$-well CMOS," Journal of Semiconductor Technology and Science, vol. 10, no. 4, pp. 309-315, 2010.

[61] W.-S. Wang, Z.-C. Wu, H.-Y. Huang, and C.-H. Luo, "Lowpower instrumental amplifier for portable ECG," in Proceedings 
of the IEEE Circuits and Systems International Conference Testing and Diagnosis (ICTD '09), Chengdu, China, April 2009.

[62] S. P. Almazan, L. I. Alunan, F. R. Gomez, J. M. Jarillas, M. T. Gusad, and M. Rosales, "Monolithic CMOS current-mode instrumentation amplifiers for ECG signals," in Proceedings of the 13th International Conference on Biomedical Engineering (ICBME '08), vol. 23, pp. 846-850, Singapore, December 2008.

[63] C. Nanda, J. Mukhopadhyay, D. Mandai, and S. Chakrabarti, "A CMOS instrumentation amplifier with low voltage and low noise for portable ECG monitoring systems," in Proceedings of the IEEE International Conference on Semiconductor Electronics (ICSE '08), pp. 54-58, Johor Bahru, Malaysia, November 2008.

[64] J.-C. Liou, T.-T. Shih, W.-C. Lin, and Y.-C. Huang, "Noninvasive ECG and EMG Electrode system for Health Monitoring and Science technology application," in Proceedings of the IEEE International Conference on Consumer Electronics (ICCE-TW '15), Taipei, Taiwan, June 2015.

[65] S. Shebi Ahammed and B. C. Pillai, "Design of Wi-Fi based mobile Electrocardiogram monitoring system on concerto platform," Procedia Engineering, vol. 64, pp. 65-73, 2013.

[66] R.-D. Chiu and S.-H. Wu, "A BAN system for realtime ECG monitoring : from wired to wireless measurements," in Proceedings of the IEEE Wireless Communications and Networking Conference (WCNC '11), pp. 2107-2112, IEEE, Cancun, Mexico, March 2011.

[67] H. Gao, X. Duan, X. Guo, A. Huang, and B. Jiao, "Design and tests of a smartphones-based multi-lead ECG monitoring system," in Proceedings of the 35th Annual International Conference of the IEEE Engineering in Medicine and Biology Society (EMBC '13), pp. 2267-2270, Osaka, Japan, July 2013.

[68] M.-C. Rosu, "Preliminary evaluation for an ECG monitoring system," in Proceedings of the 6th International Conference on Electronics, Computers and Artificial Intelligence (ECAI '14), pp. 73-80, IEEE, Bucharest, Romania, October 2014.

[69] M. Zeng, I.-Y. Chung, J.-A. Lee, and J.-G. Lee, "An on-node intelligence based energy efficient ECG monitoring system," in Proceedings of the International Conference on ICT Convergence (ICTC '11), pp. 401-405, IEEE, Seoul, South Korea, September 2011.

[70] T. Komensky, M. Jurcisin, K. Ruman, O. Kovac, D. Laqua, and P. Husar, "Ultra-wearable capacitive coupled and common electrode-free ECG monitoring system," in Proceedings of the 34th Annual International Conference of the IEEE Engineering in Medicine and Biology Society (EMBS '12), pp. 1594-1597, IEEE, San Diego, Calif, USA, September 2012.

[71] O. Özkaraca, A. H. Işik, and I. Güler, "Detection, real time processing and monitoring of ECG signal with a wearable system," in Proceedings of the International Symposium on Innovations in Intelligent SysTems and Applications (INISTA '11), pp. 424-427, tur, June 2011.

[72] M. K. Islam, M. A. Shoeb, T. Ahammad, and T. F. Nowrin, "Embedded programmable web-based ECG monitoring \& detection system using a fast algorithm," in Proceedings of the International Conference on Bioinformatics and Biomedical Technology (ICBBT '10), pp. 156-159, IEEE, Chengdu, China, April 2010.

[73] http://www.skintact.com/.

[74] http://www.medgadget.com.

[75] http://www.meddeviceonline.com.

[76] J.-Y. Baek, J.-H. An, J.-M. Choi, K.-S. Park, and S.-H. Lee, "Flexible polymeric dry electrodes for the long-term monitoring of
ECG," Sensors and Actuators, A: Physical, vol. 143, no. 2, pp. 423429, 2008.

[77] A. Gruetzmann, S. Hansen, and J. Müller, "Novel dry electrodes for ECG monitoring," Physiological Measurement, vol. 28, no. 11, pp. 1375-1390, 2007.

[78] R. Matthews, N. J. McDonald, I. Fridman, P. Hervieux, and T. Nielsen, "Nonintrusive, wearable bioelectrodes for monitoring the heart and brain," Sensors, 2007, http://www.sensorsmag .com/specialty-markets/medical-devices/nonintrusive-wearablebioelectrodes-monitoring-heart-and-bra-1412.

[79] H. W. Sharma and M. Singh, "Design and development of heart rate monitoring device with reduction of motion artefact using 3-axis accelerometer," International Journal of Emerging Technology and Advanced Engineering, vol. 4, no. 7, pp. 448-453, 2014.

[80] C.-H. Lin, S.-Y. Chen, C.-C. Yang et al., "Structural health monitoring of bridges using cost-effective 1-axis accelerometers," in Proceedings of the 2014 9th IEEE Sensors Applications Symposium (SAS '14), pp. 24-27, Queenstown, New Zealand, February 2014.

[81] H. Gjoreski, A. Rashkovska, S. Kozina, M. Luštrek, and M. Gams, "Telehealth using ECG sensor and accelerometer," in Proceedings of the 37th International Convention on Information and Communication Technology, Electronics and Microelectronics (MIPRO '14), pp. 270-274, May 2014.

[82] V. Dhivya Poorani, K. Ganapathy, and V. Vaidehi, "Sensor based decision making inference system for remote health monitoring," in Proceedings of the International Conference on Recent Trends in Information Technology (ICRTIT '12), pp. 337342, Chennai, India, April 2012.

[83] E. Kantoch, M. Smolen, P. Augustyniak, and P. Kowalski, "Wireless body area network system based on ECG and accelerometer pattern," Computing in Cardiology, vol. 38, pp. 245-248, 2011.

[84] A. Dinh, "Heart activity monitoring on smartphone," in Proceedings of the International Conference on Biomedical Engineering and Technology (IPCBEE '11), pp. 45-49, 2011.

[85] J. Lee, J. Jung, J. Lee, and Y. T. Kim, "Diagnostic device for acute cardiac disease using ECG and accelerometer," in Proceedings of the 5th International Conference on Information Science and Applications (ICISA '14), pp. 1-3, IEEE, Seoul, South Korea, May 2014.

[86] J. Penders, M. Altini, J. van de Molengraft, F. Yazicioglu, and C. Van Hoof, "A low-power wireless ECG necklace for reliable cardiac activity monitoring on-the-move," in Proceedings of the 33rd IEEE EMBS Annual International Conference (EMBC '11), Boston, Mass, USA, 2011.

[87] P. Augustyniak, M. Smoleń, Z. Mikrut, and E. Kańtoch, "Seamless tracing of human behavior using complementary wearable and house-embedded sensors," Sensors, vol. 14, no. 5, pp. 78317856, 2014.

[88] A. M. Khan, M. H. Siddiqi, and S.-W. Lee, "Exploratory data analysis of acceleration signals to select light-weight and accurate features for real-time activity recognition on smartphones," Sensors, vol. 13, no. 10, pp. 13099-13122, 2013.

[89] A. Muaremi, J. Seiter, G. Tröster, and A. Bexheti, "Monitor and understand pilgrims: data collection using smartphones and wearable devices," in Proceedings of the 2013 ACM Conference on Pervasive and Ubiquitous Computing Adjunct Publication (UbiComp '13 Adjunct), pp. 679-688, ACM, Zürich, Switzerland, 2013.

[90] W. V. Shi and M. Zhou, "Recent advances of sensors for pacemakers," in Proceedings of the International Conference on 
Networking, Sensing and Control (ICNSC '11), pp. 520-525, IEEE, Delft, The Netherlands, April 2011.

[91] T. Grosse-Puppendahl, E. Berlin, and M. Borazio, "Enhancing accelerometer-based activity recognition with capacitive proximity sensing," in Ambient Intelligence, Springer, 2012.

[92] M.-Z. Poh, N. C. Swenson, and R. W. Picard, "Motion-tolerant magnetic earring sensor and wireless earpiece for wearable photoplethysmography," IEEE Transactions on Information Technology in Biomedicine, vol. 14, no. 3, pp. 786-794, 2010.

[93] S. J. Preece, J. Y. Goulermas, L. P. J. Kenney, and D. Howard, "A comparison of feature extraction methods for the classification of dynamic activities from accelerometer data," IEEE Transactions on Biomedical Engineering, vol. 56, no. 3, pp. 871-879, 2009.

[94] M. Jafari Tadi, T. Koivisto, M. Pänkäälä, and A. Paasio, "Accelerometer-based method for extracting respiratory and cardiac gating information for dual gating during nuclear medicine imaging," International Journal of Biomedical Imaging, vol. 2014, Article ID 690124, 11 pages, 2014.

[95] A. M. Chan, N. Ferdosi, and R. Narasimhan, "Ambulatory respiratory rate detection using ECG and a triaxial accelerometer," in Proceedings of the 35th Annual International Conference of the IEEE Engineering in Medicine and Biology Society (EMBC '13), pp. 4058-4061, Osaka, Japan, July 2013.

[96] G.-Z. Liu, Y.-W. Guo, Q.-S. Zhu, B.-Y. Huang, and L. Wang, "Estimation of respiration rate from three-dimensional acceleration data based on body sensor network," Telemedicine Journal and e-Health, vol. 17, no. 9, pp. 705-711, 2011.

[97] Y. Okada, T. Y. Yoto, T. Suzuki, S. Sakuragawa, and T. Sugiura, "Wearable ECG recorder with acceleration sensors for monitoring daily stress: office work simulation study," in Proceedings of the 35th Annual International Conference of the IEEE Engineering in Medicine and Biology Society (EMBC '13), pp. 4718-4721, July 2013.

[98] L. Oudre, A. Lung-Yut-Fong, and P. Bianchi, "Segmentation of accelerometer signals recorded during continuous treadmill walking," in Proceedings of the 19th European Signal Processing Conference (EUSIPCO '11), pp. 1564-1568, Barcelona, Spain, September 2011.

[99] E. Sejdić, K. A. Lowry, J. Bellanca, M. S. Redfern, and J. S. Brach, "A Comprehensive Assessment of Gait Accelerometry Signals in Time, Frequency and Time-Frequency Domains," IEEE Transactions on Neural Systems and Rehabilitation Engineering, vol. 22, no. 3, pp. 603-612, 2014.

[100] F. Studnička, P. Šeba, D. Jezbera, and J. Kř́iž, "Continuous monitoring of heart rate using accelerometric sensors," in Proceedings of the 35th International Conference on Telecommunications and Signal Processing (TSP '12), pp. 559-561, IEEE, Prague, Czech Republic, July 2012.

[101] A. I. Bhuyan and T. C. Mallick, "Gyro-accelerometer based control of a robotic arm using AVR microcontroller," in Proceedings of the 9th International Forum on Strategic Technology (IFOST '14), pp. 409-413, IEEE, Cox's Bazar, Bangladesh, October 2014.

[102] Y. Chen, J. M. Oliveira, and I. W. Hunter, "Sensor architecture for a two-actuator robotic endoscope tip," in Proceedings of the 33rd Annual International Conference of the IEEE Engineering in Medicine and Biology Society (EMBS '11), pp. 8340-8343, IEEE, Boston, Mass, USA, September 2011.

[103] C. Liu and Z. Wang, "Design and realization of data acquiring system for vehicle speed sensor and gyroscope," in Proceedings of the 2nd IEEE International Conference Information Management and Engineering (ICIME '10), April 2010.
[104] G. Li, F. Wang, G. Xiao, G. Wei, P. Zhang, and X. Long, "Temperature compensation method using readout signals of ring laser gyroscope," Optics Express, vol. 23, no. 10, pp. 1332013332, 2015.

[105] D. Xia, S. Chen, and S. Wang, "Development of a prototype miniature silicon microgyroscope," Sensors, vol. 9, no. 6, pp. 4586-4605, 2009.

[106] X. Chen, X. Hu, R. Ren et al., "Noninvasive ambulatory monitoring of the electric and mechanical function of heart with a multifunction wearable sensor," in Proceedings of the 38th Annual IEEE Computer Software and Applications Conference Workshops (COMPSACW '14), pp. 662-667, Vasteras, Sweden, July 2014.

[107] K. Brzostowski, J. Drapala, and J. Swiatek, "Data-driven models for eHealth applications," International Journal of Computer Science and Artificial Intelligence, vol. 3, no. 1, pp. 1-9, 2013.

[108] M. Khazraee, A. R. Zamani, M. Hallajian et al., "A novel hardware implementation for joint heart rate, respiration rate, and gait analysis applied to body area networks," in Proceedings of the IEEE International Symposium on Circuits and Systems (ISCAS '13), pp. 1889-1892, Kottayam, India, May 2013.

[109] G. Gargiulo, P. Bifulco, M. Cesarelli et al., "An ultra-high input impedance ECG amplifier for long-term monitoring of athletes," Medical Devices: Evidence and Research, vol. 3, no. 1, pp. 1-9, 2010.

[110] T. J. Sullivan, S. R. Deiss, and G. Cauwenberghs, "A lownoise, non-contact EEG/ECG sensor," in Proceedings of the IEEE Biomedical Circuits and Systems Conference Healthcare Technology (BiOCAS '07), pp. 154-157, November 2007.

[111] J. Gomez-Clapers, E. Serrano-Finetti, R. Casanella, and R. Pallas-Areny, "Can driven-right-leg circuits increase interference in ECG amplifiers?" in Proceedings of the 33rd Annual International Conference of the IEEE Engineering in Medicine and Biology Society (EMBS '11), pp. 4780-4783, Boston, Mass, USA, September 2011.

[112] A. Q. Bhat, V. Kumar, and S. Kumar, "Design of ECG data acquisition system," International Journal of Advanced Research in Computer Science and Software Engineering, vol. 3, no. 4, pp. 676-680, 2013.

[113] K. Wang, S. Ma, J. Feng, W. Zhang, M. Fan, and D. Zha, "Design of ECG signal acquisition system based on DSP," in Proceedings of the International Workshop on Information and Electronics Engineering, Procedia Engineering, vol. 29, pp. 37633767, Elsevier, Amsterdam, Netherlands, 2012.

[114] E. Richard and A. D. C. Chan, "Design of a gel-less twoelectrode ECG monitor," in Proceedings of the IEEE International Workshop on Medical Measurements and Applications (MeMeA '10), pp. 92-96, May 2010.

[115] J. Krishnan, N. D. Khambete, A. Rajan, and B. Benjamin, "Low power multiparameter biopotential amplifier system," International Journal of Science and Research, vol. 2, no. 11, pp. 186-189, 2013.

[116] M. Burke and C. Jassambo, "An ultra-low power dry-electrode ECG amplifier having optimized low-frequency response and CMRR," Recent Researches in Circuits and Systems, pp. 54-59, 2010.

[117] C. Assambo and M. J. Burke, "Amplifier input impedance in dry electrode ECG recording," in Proceedings of the 31st Annual International Conference of the IEEE Engineering in Medicine and Biology Society (EMBC '09), pp. 1774-1777, IEEE, Minneapolis, Minn, USA, September 2009. 
[118] O. T. Inan and G. T. A. Kovacs, "An $11 \mu \mathrm{w}$, two-electrode transimpedance biosignal amplifier with active current feedback stabilization," IEEE Transactions on Biomedical Circuits and Systems, vol. 4, no. 2, pp. 93-100, 2010.

[119] E. M. Spinelli, R. Pallàs-Areny, and M. A. Mayosky, "AC-coupled front-end for biopotential measurements," IEEE Transactions on Biomedical Engineering, vol. 50, no. 3, pp. 391-395, 2003.

[120] Y.-W. Bai, C.-Y. Cheng, C.-K. Lu, C.-H. Huang, Y.-T. Chen, and Y.-N. Lin, "Adjustable $60 \mathrm{~Hz}$ noise reduction and ECG signal amplification of a remote electrocardiogram system," in Proceedings of the 20th IEEE Instrumentation and Measurement Technology Conference (IMTC '03), pp. 197-202, Vail, Colo, USA, May 2003.

[121] S. Song, M. Rooijakkers, P. Harpe et al., "A low-voltage chopperstabilized amplifier for fetal ECG monitoring with a 1.41 power efficiency factor," IEEE Transactions on Biomedical Circuits and Systems, vol. 9, no. 2, pp. 237-247, 2015.

[122] C.-C. Tu and T.-H. Lin, "Analog front-end amplifier for ECG applications with feed-forward EOS cancellation," in Proceedings of the International Symposium on VLSI Design, Automation and Test (VLSI-DAT '14), Hsinchu, Taiwan, April 2014.

[123] S. Wang, Y. Wang, L. Chen et al., "A 192nW inverter-based chopper instrumentation amplifier for micropower ECG applications," in Proceedings of the 12th IEEE International Conference on Solid-State and Integrated Circuit Technology (ICSICT '14), October 2014.

[124] J. Zhang, L. Wang, and B. Li, "Design of low-offset lowpower CMOS amplifier for biosensor application," Journal of Biomedical Science and Engineering, vol. 2, no. 7, pp. 538-542, 2009.

[125] D. Rowlands, D. A. James, C. Vanegas, S. Rao, and P. Lisner, "Design and fabrication of an ECG amplifier on silicon using standard CMOS process," in Proceedings of the Second IEEE International Conference on Sensors: IEEE Sensors 2003, pp. 1348-1352, October 2003.

[126] B. Lee and T. Higman, "1.2V constant-gm rail-to-rail CMOS Op-Amp input stage with new overlapped transition regions technique for ECG amplifier," in Proceedings of the 35th Annual International Conference of the IEEE Engineering in Medicine and Biology Society (EMBC '13), pp. 3451-3454, IEEE, Osaka, Japan, July 2013.

[127] M. Ghamati and M. Maymandi-Nejad, "A low-noise low-power MOSFET only electrocardiogram amplifier," in Proceedings of the 21st Iranian Conference on Electrical Engineering (ICEE '13), Mashhad, Iran, May 2013.

[128] C.-C. Wu, W.-C. Kuo, H.-J. Wang et al., "A pliable and batteryless real-time ECG monitoring system-in-a-patch," in Proceedings of the International Symposium on VLSI Design, Automation and Test (VLSI-DAT '15), IEEE, April 2015.

[129] D. Pani, A. Dessì, J. F. Saenz-Cogollo, G. Barabino, B. Fraboni, and A. Bonfiglio, "Fully textile, PEDOT:PSS based electrodes for wearable ECG monitoring systems," IEEE Transactions on Biomedical Engineering, vol. 63, no. 3, pp. 540-549, 2016.

[130] http://www.ti.com.

[131] http://www.analog.com.

[132] D. M. D. Ribeiro, M. F. M. Colunas, F. A. F. Marques, J. M. Fernandes, and J. P. S. Cunha, "A real time, wearable ECG and continous blood pressure monitoring system for first responders," in Proceedings of the 33rd Annual International Conference of the IEEE Engineering in Medicine and Biology Society (EMBS '11), pp. 6894-6898, Boston, Mass, USA, September 2011.
[133] K. Wang, S. Ma, J. Feng, W. Zhang, M. Fan, and D. Zhao, "Design of ECG signal acquisition system based on DSP," Procedia Engineering, vol. 29, pp. 3763-3767, 2012.

[134] J. N. Chi, Y. T. Yan, M. C. Liu, and L. Yang, "The development of a Portable ECG monitor based on DSP," in Proceedings of the ELSEVIER, International Conference on Medical Physics and Biomedical Engineering (ICMPBE '12), vol. 33 of Physics Procedia, pp. 765-774, Qingdao, China, 2012.

[135] J. Chai, “The design of mobile ECG monitoring system," in Proceedings of the 4th IEEE International Conference on Electronics Information and Emergency Communication (ICEIEC '13), pp. 148-151, IEEE, Beijing, China, November 2013.

[136] G. Yang, X. Cai, F. Wang, S. Cu, and L. Zhao, "Research of portable ECG monitoring device," in Advances in Computer, Communication, Control and Automation, vol. 121 of Lecture Notes in Electrical Engineering, pp. 213-220, Springer, Berlin, Germany, 2011.

[137] D. Campillo, H. Torres, R. Gonzalez, K. Valdes, and R. Lopez, "A portable device for a modular system of patient ECG monitoring," Computing in Cardiology, vol. 41, pp. 1077-1079, 2014.

[138] C. Ken and L. Xiaoying, "A Zigbee based mesh network for ECG monitoring system," in Proceedings of the 4th International Conference on Bioinformatics and Biomedical Engineering (iCBBE '10), pp. 1-4, Chengdu, China, June 2010.

[139] E. B. Alzate and F. M. Martinez, "ECG monitoring system based on ARM9 and mobile phone technologies," in Proceedings of the IEEE Andean Council International Conference (ANDESCON '10), September 2010.

[140] W. Shin, Y. D. Cha, and G. Yoon, "ECG/PPG integer signal processing for a ubiquitous health monitoring system," Journal of Medical Systems, vol. 34, no. 5, pp. 891-898, 2010.

[141] X. Guo, W. Chen, X. Xu, and H. Li, "The research of portable ECG monitoring system with USB host interface," in Proceedings of the IEEE 3rd International Conference on BioMedical Engineering and Informatics (BMEI '10), pp. 1614-1618, Yantai, China, October 2010.

[142] http://www.atmel.com/products/smart-energy/wireless-communications/default.aspx.

[143] https://www.lsr.com/white-papers/soc-vs-sdr-for-wireless-product-design. 


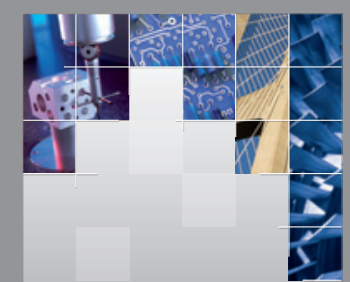

\section{Enfincering}
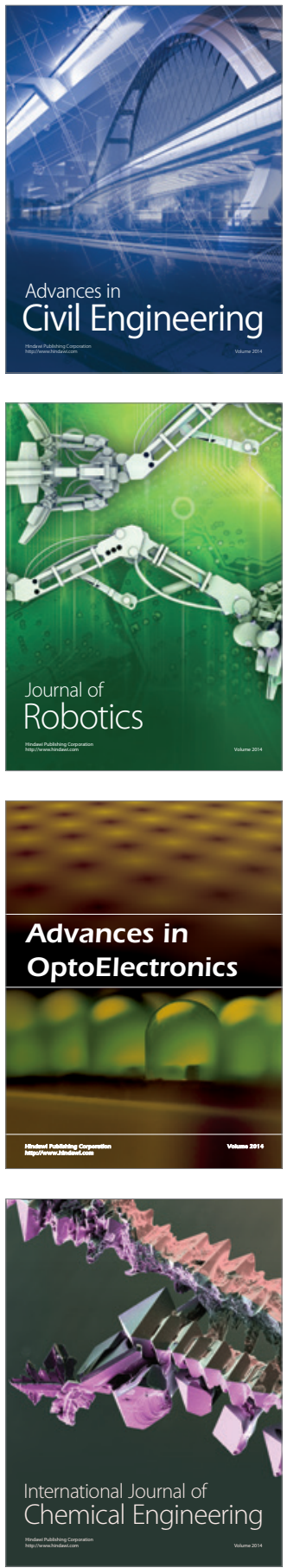

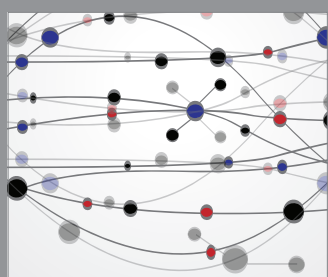

The Scientific World Journal

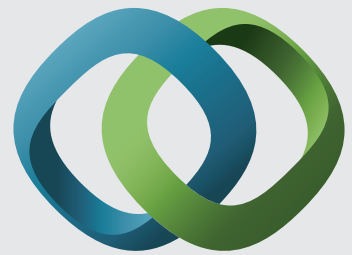

\section{Hindawi}

Submit your manuscripts at

http://www.hindawi.com
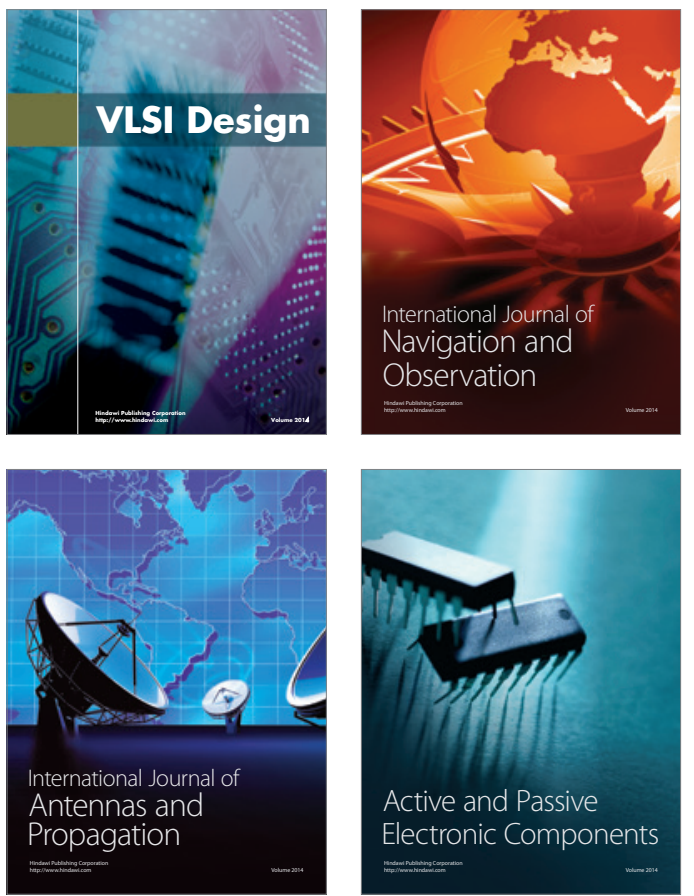
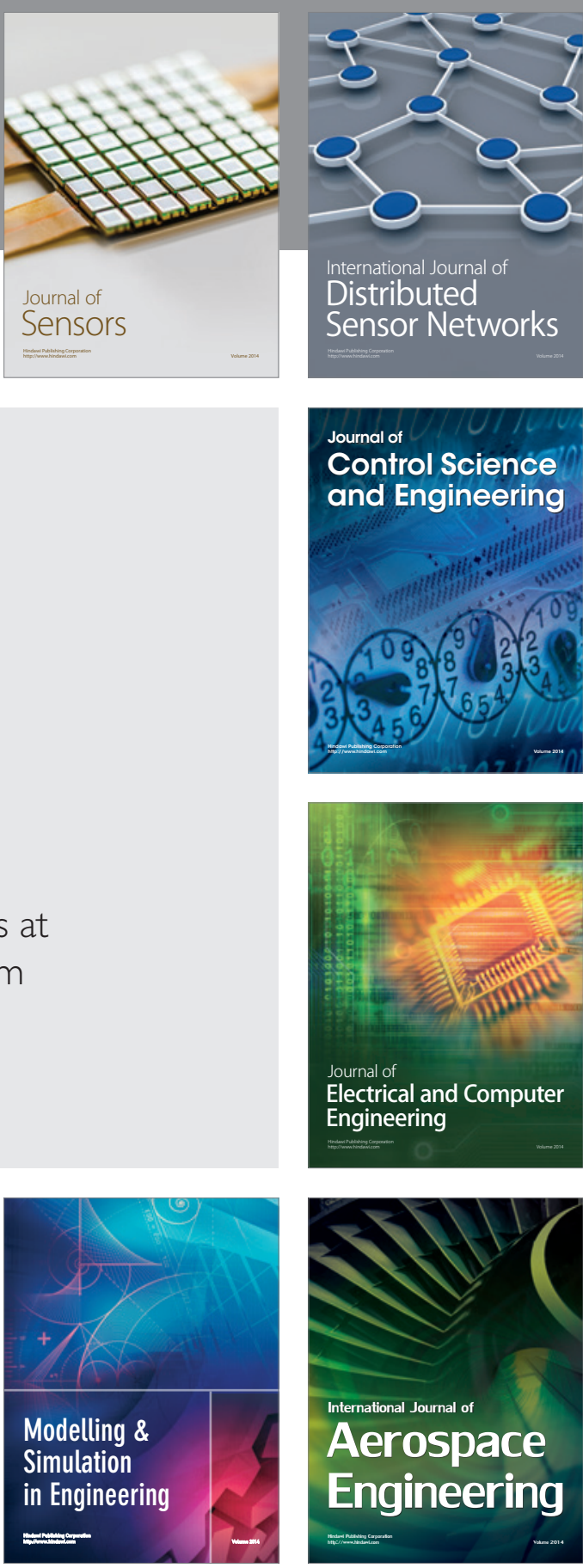

International Journal of

Distributed

Sensor Networks

Journal of

Control Science

and Engineering
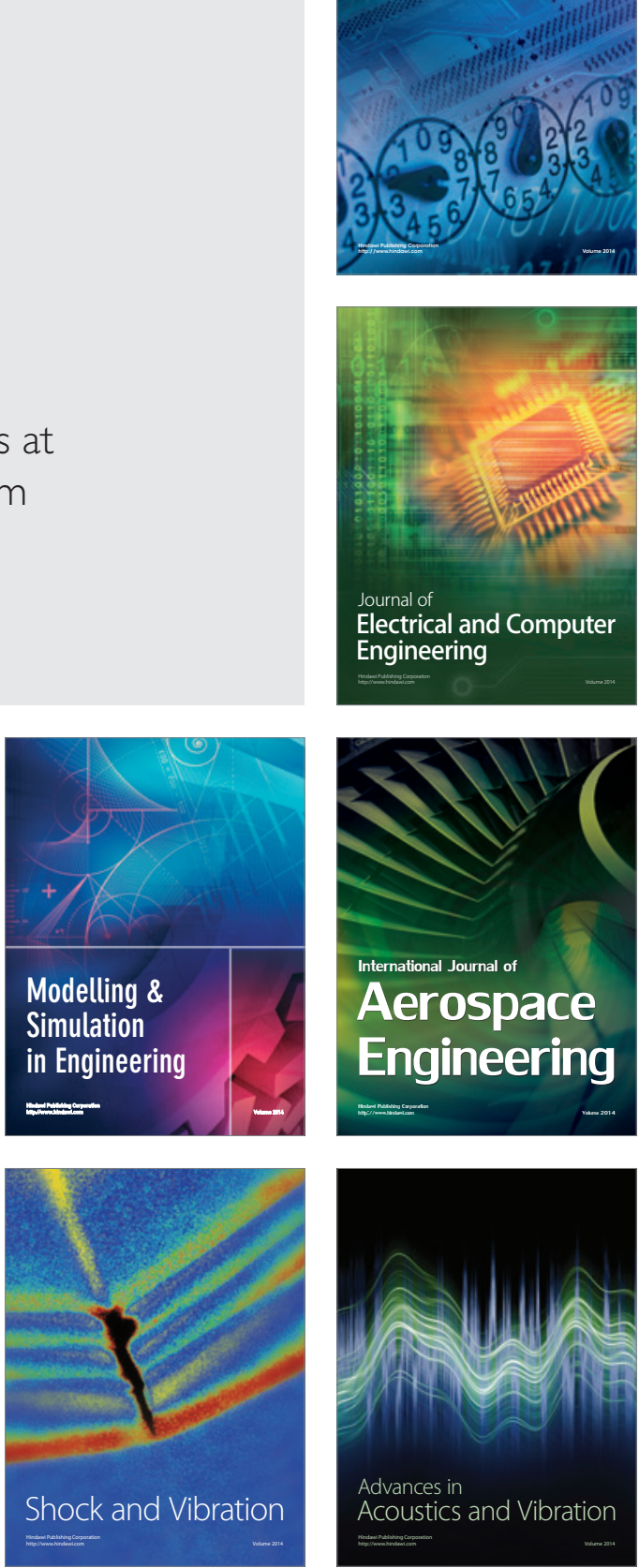